Portland State University

PDXScholar

Spring 7-21-2017

\title{
Contexts of Reception and Constructions of Islam: Second Generation Muslim Immigrants in Post-9/11 America
}

Shahriyar Smith

Portland State University

Follow this and additional works at: https://pdxscholar.library.pdx.edu/open_access_etds

Part of the Islamic Studies Commons, Political Science Commons, and the Sociology Commons Let us know how access to this document benefits you.

\section{Recommended Citation}

Smith, Shahriyar, "Contexts of Reception and Constructions of Islam: Second Generation Muslim Immigrants in Post-9/11 America" (2017). Dissertations and Theses. Paper 3766.

https://doi.org/10.15760/etd.5650

This Thesis is brought to you for free and open access. It has been accepted for inclusion in Dissertations and Theses by an authorized administrator of PDXScholar. Please contact us if we can make this document more accessible: pdxscholar@pdx.edu. 
Contexts of Reception and Constructions of Islam:

Second Generation Muslim Immigrants in Post-9/11 America

\title{
by
}

Shahriyar Smith

A thesis submitted in partial fulfillment of the requirements for the degree of

\author{
Master of Science \\ in \\ Sociology
}

Thesis Committee:

Alex Stepick, Chair

Jose Padin

Maura Kelly

Portland State University

2017 
(C) 2017 Shahriyar Smith 


\begin{abstract}
The World Trade Center attacks on September 11, 2001 fundamentally transformed the context of reception for Muslim immigrants in the U.S., shifting it from neutral to negative while also brightening previously blurred boundaries between established residents and the Muslim minority. This study explores how secondgeneration Muslim immigrants have experienced and reacted to post-9/11 contexts of reception. It is based on an analysis of ten semi-structured in-depth interviews that were conducted throughout the Portland Metropolitan Area from January to April of 2016. It finds experiences of discrimination to be primarily affected by two factors: public institutions and gender. It also finds, furthermore, that research participants react to negative post-9/11 contexts of reception by redrawing bright boundaries to include themselves within the American mainstream. Because Islam itself has become politicized within post-9/11 contexts of reception, this study also explores how secondgeneration Muslim immigrants construct and maintain religious meaning as a form of political identity. It finds that research participants unilaterally construct a Localized Islam that is dynamic and variable in its response to familial and social pressures. The thesis concludes by putting forward a typology outlining its four primary forms of localization within contemporary social and political environments.
\end{abstract}




\section{Acknowledgments}

First and foremost, I would like to thank my Chair, Alex Stepick, for his tireless investment of time and energy on my behalf and for his constant optimism in response to my ambitions. I would also like to thank Jose Padin, whose constant encouragement and uncompromising critique kept me honest and driven. Finally, I would like to thank Maura Kelly, who took the time to sit down and talk with me often and whose grace and good manners have been instructive to me on more than one occasion. 


\section{Table of Contents}

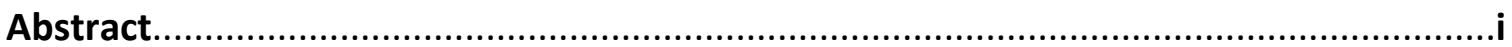

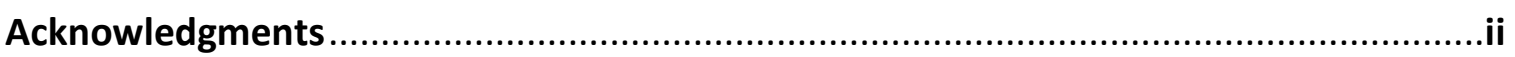

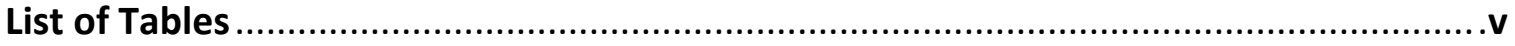

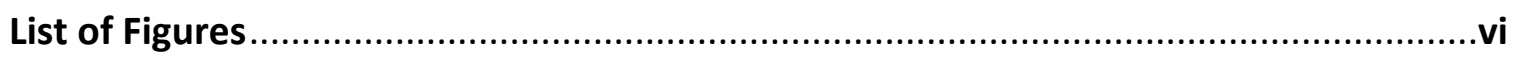

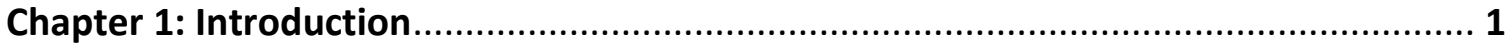

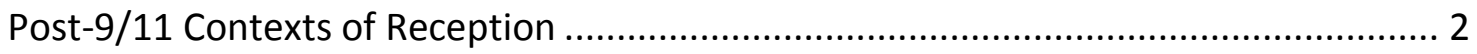

Brightening a Once Blurred Boundary .................................................................. 5

The Critical Intersection of Second Generation Muslim Immigrants in the U.S............ 9

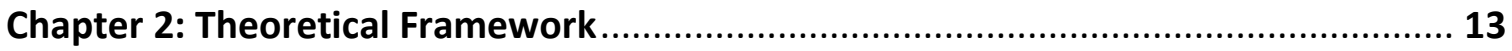

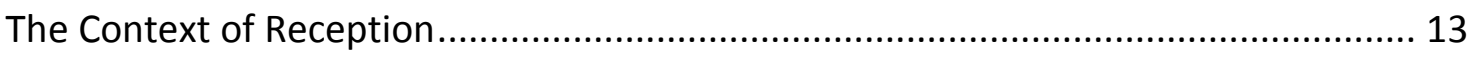

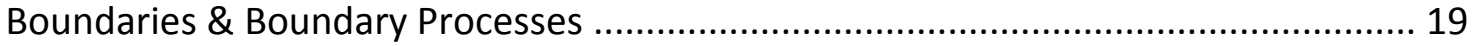

The Role of Religion: Linear vs. Reactive Identity ................................................. 24

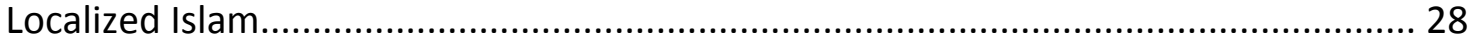

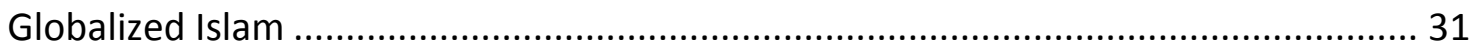

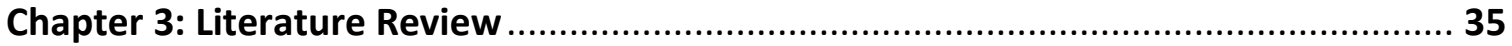

Research on the Second Generation in Europe .................................................... 35

Research on the Second Generation Muslim Immigrants in the U.S. ....................... 41

Islamic Religious Identity Across Europe and the U.S. .......................................... 47

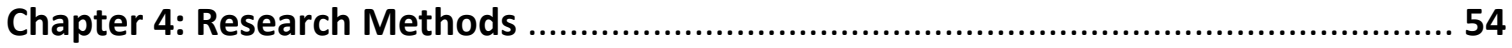

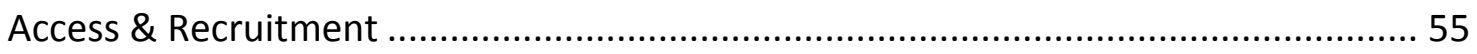

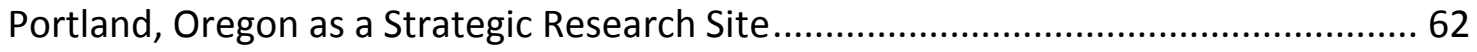

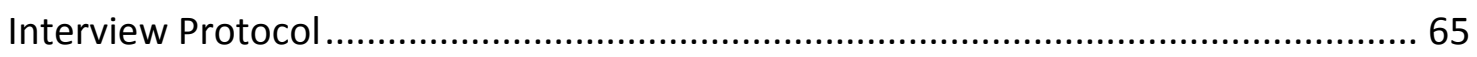

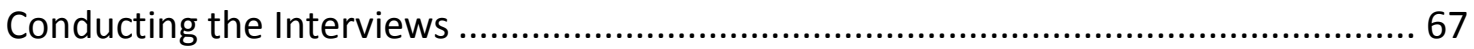

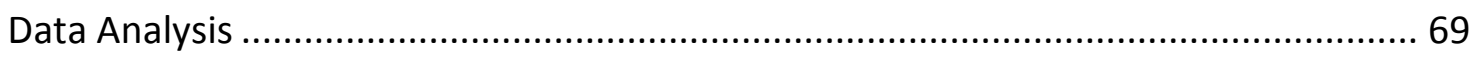

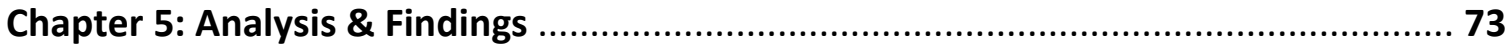

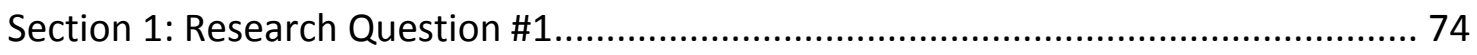

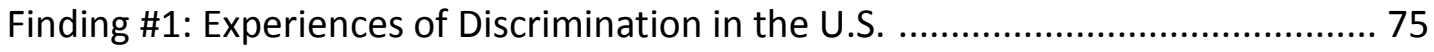

Finding \#2: Resilience among the Second Generation...................................... 89 
Finding \#3: Shifting the Bright Boundary

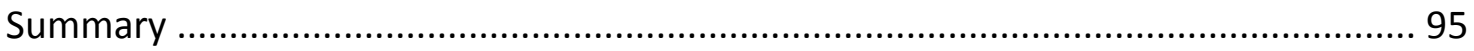

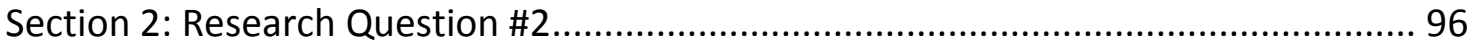

Finding \#4: Selective Acculturation: The Role of Family \& Society........................ 96

Constructions of Islam: Four Vignettes........................................................ 101

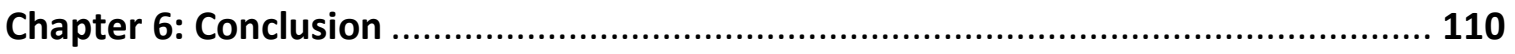

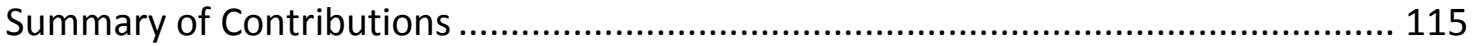

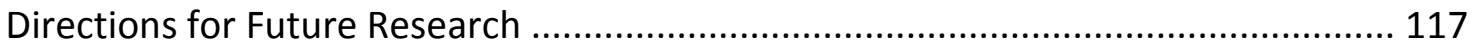

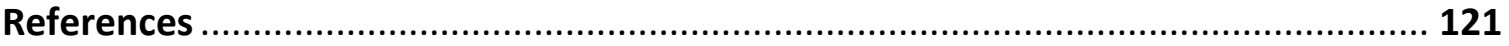

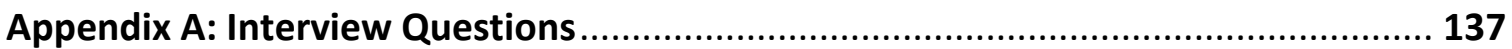

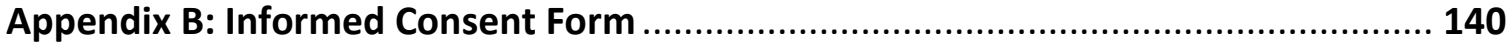




\section{List of Tables}

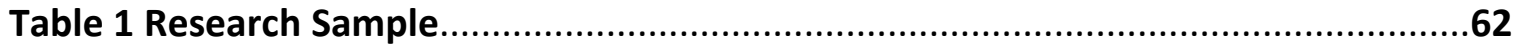

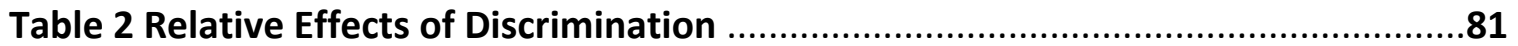

Table 3 Family, U.S. Society \& The Construction of Islam.....................................100 


\section{List of Figures}

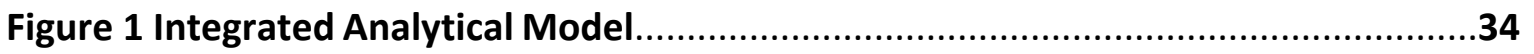




\section{Chapter 1}

\section{Introduction}

The World Trade Center attacks on September 11, 2001 served as the pivotal event whereby previously neutral contexts of reception once confronting Muslim immigrants in the U.S. have been fundamentally transformed. Since then, Muslims in the U.S. have been met by a decidedly negative context of reception, one where they are disproportionately visible and within which their suitability as Americans is questioned on the basis of their religious identity. They "are asked to explain who they are, what they believe in and what they stand for [...] they have to manage their Islamic identity in host countries that often portray Muslims negatively and define Islam as a religion of violence" (Yildiz \& Verkuyten, 2012:360).

While such calls have been publicly directed toward Muslim immigrants in both Europe and North America (Alexander, 2013; Naber, 2006), different types of social boundaries have separated immigrants and natives on each side of the Atlantic divide. Alba (2005) has distinguished between 'bright' boundaries for Muslim immigrants in Europe, where "the distinction involved is unambiguous, so that individuals know at all times which side of the boundary they are on" (22) and 'blurred' boundaries for Mexican immigrants in the U.S, which involve "zones of self-presentation and social representation that allow for ambiguous locations with respect to the boundary." This 
research also emphasizes how previously blurred boundaries have also been made bright for Muslim immigrants within post-9/11 contexts of reception, further indicating the extent and nature of the environmental shift toward them.

\section{Post-9/11 Contexts of Reception}

The argument for recognizing 9/11 as a pivotal event that shifted a previously neutral context of reception to negative is based upon two key observations. The first is that there is a significant difference in the context of reception for Muslims before and after 2001. If the 9/11 attacks have in fact shifted the context of reception, its role as a 'pivotal event' should be clearly delineative. Such a distinction should also make clear that there are meaningful differences between the two periods sufficient to classify them as comparatively 'neutral' and 'negative'.

The second is that Muslim immigrants are now disproportionately visible, due in large part to the renewed salience of Islamic religious identity in post-9/11 America. Historically, immigrant groups who have experienced disproportionate visibility have been seen as posing a special challenge to assimilation (Alba \& Nee, 2003). If post-9/11 contexts of reception have in fact represented a shift from neutral to negative, the disproportionate visibility of Muslim immigrants in the U.S. should also be reflected in the problematization of Islamic religious identity in the public sphere.

\section{9/11 as a 'Pivotal Event'}

The World Trade Center attacks on September 11, 2001 "were perhaps the single most important turning point in the American Muslim experience" according to 
Yenigun (2004:40). Despite the fact that the history of violent Islamic extremism in the U.S. began well before then, pre-9/11 contexts of reception appear to have been comparatively neutral for Muslim immigrants and their children (Portes \& Rumbaut, 2006). Vidino (2009), for example, outlines the history of homegrown terror networks inspired by radical Islamic extremism in substantial detail, estimating that "in the 1990's between 1,000 and 2,000 volunteers left the United States to fight or train with various jihadist outfits throughout the world" (5). Similarly, Yenigun (2004) observes that "after the Gulf War, and especially after the World Trade Center attack of 1993 and the embassy bombings in 1998, coverage of Muslims started to occupy a prominent place in the news" (40). It was not until 9/11 that U.S. media began reflexively attributing the phenomenon of terrorism to Islamic fundamentalism, and "people who had Muslim origins" (63).

Jihadist networks, "which were virtually ignored before 9/11" (Vidino, 2004:6) suddenly became a commonly understood security concern in mainstream public discourse. Individual Muslims became potential suspects as the 'war on terror' "took on local form on the streets, subjecting persons whose bodies, names, dress, or other markers signified an Arab, Middle Eastern, or Muslim identity to increased threats of harassment, violence, and intimidation" (Naber, 2006:235). Before 9/11, terrorism was an overarching media frame that included radical Islamic extremism. After 9/11, Islam itself began to constitute the overarching media frame for terrorism instead (Semati, 2010; Kumar, 2010; Bail, 2012). The evident contrast between U.S. attitudes toward 
Muslims and the relation between Islam and terrorism, before and after $9 / 11$, suggests that the event did indeed act as a critical 'turning point' that can be seen to legitimately demarcate two distinct periods.

\section{Disproportionate Visibility}

One of the most prominent and centrally-defining features of post-9/11 contexts of reception is the disproportionate visibility of Islam and Muslim immigrants. Estimated at less than 1 percent of the overall population, the 2.3 million Muslims living in the U.S. "currently encounter far greater hostility than members of any other religious group" (Voas \& Fleischmann, 2012:538). Following 9/11, "the Muslim population was no longer a silent minority. It became visible by virtue of the attention lavished on it by the media, nationally and internationally, and this served to propel the population into the public sphere" (Lynch \& Veale, 2008). Here a minority has been made visible on the basis of their faith identity. In this context they have not only been subjected to Orientalist depictions of the 'Muslim other' (Mishra, 2008; Kumar, 2010), but also thrust into public debate as public figures - underscoring what Gole (2011) refers to as the "tumultuous transition of Muslims from the status of the invisible migrant-worker to that of visible Muslim citizenship" (383).

In their discussion concerning how pivotal events may shift contexts of reception from positive to negative, Stepick \& Dutton Stepick (2009) specifically highlight the potential of such shifts to shock immigrants and natives alike into an awareness of a 
particular group's "'otherness' vis-à-vis the national social and political landscape" (8).

The disproportionate visibility of Muslim immigrants in the U.S. reflects this otherness, I have here argued, in the context of their religious identity and its implicit association with terrorism. When combined with the pivotal shift in attitudes and perceptions toward Muslims brought on by $9 / 11$, the disproportionate visibility of Muslim immigrants suggests the contemporary social and political environment to be an exemplar of a changed context of reception.

\section{Brightening a Once Blurred Boundary}

A secondary focus of this research concerns the effect of post-9/11 contexts of reception on the social boundary defining the distinction between immigrant and native. Alba (2005) distinguishes between 'bright' boundaries, where "the distinction involved is unambiguous, so that individuals know at all times which side of the boundary they are on" (22) and 'blurred' boundaries, which involve "zones of selfpresentation and social representation that allow for ambiguous locations with respect to the boundary." A key effect of post-9/11 contexts of reception has been to make a previously blurred boundary bright for second-generation Muslim immigrants in the U.S., and is evidenced by three distinct developments: the securitization of Islam, the political instrumentalization of Muslims, and the rise of Islamophobia.

The Securitization of Islam \& Political Instrumentalization of Muslims 
The emergence of a bright boundary can be seen in a number of ways. Both Wike \& Grim (2010) and Nisbet et. al. (2011) observe that public attitudes toward Muslims and Islam have been driven largely by threat perceptions since $9 / 11$. In a more specific analysis of this development, Jocelyn Cesari (2012) refers to the 'securitization' of European Muslims in this context: "Securitization refers to exceptional measures and procedures outside the rule of law, justified by emergency situations that threaten the survival of political community" (433). This has been accomplished primarily by relying on Orientalist modes of thought and action that push controversial ideologies concerning Islam and the West "into the taken-for-granted 'naturalized' world of common sense" (Kumar, 2010:2). For example, the idea that Islam is inherently imperialistic and violent, and moreover that individual Muslims are simply proxies for both Islamic imperialism and values antithetical to contemporary Western norms, harnesses circumstantial truths about a small but significant minority and applies them, in toto, to Islam generally and Muslims everywhere. In this way, securitization makes public safety and security a categorically supraordinate concern in relation to Islam and Muslim immigrants. In this way, furthermore, public fear and hostility have become aligned with security policy in such a way that a bright boundary is not only required but actively reinforced.

Seizing on the idea of Islam as an existential threat in this 'commonsense' way, U.S. political actors have relied on exploiting fears of a Muslim threat for political gain, involving "the promotion of negative depictions and the assumption that they are, at 
the least, threatening and implacable nemeses" (Sinno, 2012:219). If the salience of public perceptions toward Muslims on one hand and security fears related to terrorism on the other has required the brightening of a once blurred boundary, the political instrumentalization of Muslims in the U.S. has actively relied upon its deployment as a salient distinction in the national public arena. In both cases, the securitization and political instrumentalization of Muslim immigrants and Islam evidences the formation and intensification of a bright boundary for Muslims in the U.S.

\section{Islamophobia}

Further evidence for the role of post-9/11 contexts of reception in establishing and reinforcing a bright boundary for Muslim immigrants lies in the documented rise of Islamophobia. Bail's (2015) analysis of Islamophobia's dominant rise within the U.S. media between 2001 and 2008 emphasizes as a critical explanatory factor the role of both public fear and hostility toward Muslims in amplifying the voice of 'anti-Muslim fringe groups' within the public discourse. Taken together, the review of research literature offered so far is suggestive of a climate of fear - one which has not only driven a new hostility toward Muslim immigrants but also allowed dominant understandings of Islam as monolithic, misogynistic and inherently violent to become 'commonsense' (Kumar, 2010).

For their part, scholars have taken two primary approaches toward Islamophobia. The first focuses on Islamophobia as defined by "Indiscriminate negative 
attitudes or emotions directed at Islam or Muslims" (Bleich, 2012: 182). Because the term "has evolved from a primarily political concept toward one increasingly deployed for analytical purposes" (180), the focus remains on the "history, presence, dimensions, intensity, causes, and consequences of anti-Islamic and anti-Muslim sentiments." Other authors have extended such analyses to include the 'racialization' of Muslims (Sayyid \& Vakil, 2010; Naber, 2006) in the broader historical and colonial context of Western nations.

The second approach has focused on fear rather than hostility toward Muslims and Islam as the basis for approaching and understanding Islamophobia. Marranci (2004), for example, argues that Islamophobia "has its last raison d'etre in the fear of multiculturalism and its consequences" (105). It is the 'transruptive' potential of Islam and Muslim immigrants within a truly multicultural society that, in this view, ultimately grounds fear-driven public discourses in the post-9/11 West. "It is not the immigrant that anguishes [author of the controversial text Clash of Civilizations, Samuel] Huntington, but multiculturalism and the connected risk of transculturation processes" (114).

In both cases, the rise of Islamophobia can be seen as a result of the emergence of negative post-9/11 contexts of reception and the formation of bright boundaries for Muslims in the U.S. And it is these bright boundaries, driven by the fear and hostility that define post-9/11 contexts of reception, that 'anti-Muslim fringe groups' have exploited in order to disproportionately amplify their voice in the media and make a 
sincerely broad-based appeal to the quintessential nativism that drives the basic protective impulses of a polity. In this way, bright boundaries for Muslims in the fields of politics and the media interact with and mutually-reinforce post-9/11 contexts of reception. The location of Muslim immigrants no longer appears to be ambiguous with respect to the boundary.

\section{The Critical Intersection of Second Generation Muslim Immigrants in the U.S.}

Abbas (2012) has discussed the relationship between Islamophobia and Radicalization as 'symbiotic' in his research on the effects of counter-radicalization policies among Muslim youth in Britain, concluding that the debate over British multiculturalism "in effect securitises a focus on integration, which then problematises the 'Muslimness' of Muslims in relation to questions of political violence and extremism" (Abbas, 2012:346). While emphasizing Alba's (2005) identification of bright boundaries for Muslim immigrants in Europe, Abbas's (2012) research also highlights an important intersection for Muslim immigrants in both Europe and the U.S. The rise of Islamophobia and the radicalization of second-generation Muslim immigrants have been documented in research on both continents (Post \& Sheffer, 2006; Bail, 2012), yet comparatively little work, especially in the U.S., has examined Muslim immigrants at the crossroads of this critical intersection.

Furthermore, while most first-generation Muslim immigrants are able to reflect on their experiences in the U.S. pre and post-9/11, a progressively smaller share of the 
second generation understands both sides of this historical demarcation through lived experience. For many second-generation Muslim immigrants, 9/11 has shaped the only social and political environment they have ever known. Where members of the first generation have often arrived with well-defined cultural and religious identities formed in their country of origin (Roy, 2004), the second generation has been raised and socialized within social and political environments defined largely by Islamophobia (Portes \& Rumbaut, 2006). For these reasons, young adult second-generation Muslim immigrants are the primary focus of this study.

\section{Motivations for Research}

As a comparatively understudied population in the U.S. this group also exists at a critical intersection between Islamophobia at home and the recruitment efforts of radical extremists abroad. They are comparatively understudied relative to the first generation of Muslim immigrants more generally. And more particularly, they are understudied relative to other immigrant groups in the U.S, especially in relation to their European counterparts, and have come to constitute a vulnerable population in this regard.

Abbas' (2012) discussion of the symbiotic relationship between Islamophobia and radicalization, and their potential to mutually-reinforce and exacerbate one another, is a point of vulnerability for the larger society as well, I would argue, because as a nation of immigrants the health and vitality of the United States has been fundamentally linked to the eventual assimilation of immigrant groups (Alba \& Nee, 
2003). The burdensome effects of social and economic discrimination, by contrast, have never boded well for immigrants or the larger society.

Research Questions

Are second generation Muslim immigrants continuing to assimilate as research indicates their forebears have done before them (Gest, 2012)? Or are the effects of disproportionate visibility and Islamophobia giving rise to reactive ethnicity (Portes \& Rumbaut, 2006)? These are deeply consequential questions that require scholarly exploration, and which affect both Muslim immigrants themselves as well as the host nation to which they belong. This research asks therefore: How have the children of Muslim immigrants in the U.S. experienced and reacted to post-9/11 social and political environments?

The renewed salience of Islamic religious identity in post-9/11 America has put Islam squarely at issue in political terms for second-generation Muslim immigrants. This research also asks, in addition: How do second-generation Muslim immigrants in the U.S. construct and maintain religious meaning? In the midst of Islamophobia and 'culture talk' concerning the compatibility of Islamic and Western values, what Islam actually 'is' among this population has become a legitimate, and so far understudied empirical question.

Research Goals

What follows is an exploratory study on young adult, second-generation Muslim immigrants in the U.S. Beyond an answer to the research questions, it has two 
additional secondary goals: to give voice to an underrepresented group and to identify hypothesis and fertile grounds for future research. This is done primarily through indepth interviews designed to explore possible bases for analyzing both the effects of post-9/11 environments and the political claims of contemporary post-9/11 discourses in relation to what Islam is and, by extension, who exactly Muslim immigrants in the U.S. are. More particularly, this thesis aims to explore what Islam is for young adult second generation Muslims and how these immigrants view themselves and assimilation into U.S. society. Being exploratory in nature, this study seeks to answer the two research questions with the recognition that the answers will be tentative, given the modest empirical sample and methodological limitations (discussed below). 


\section{Chapter 2}

\section{Theoretical Framework}

This section develops my theoretical framework for addressing how 9/11 affects the assimilation of second-generation Muslim immigrants. I begin with an outline of the context of reception, the concept most directly relevant to the events of $9 / 11$, and indicate how it can vary both over time and place. Next, I highlight the role of boundary processes within Alba \& Nee's (2003) contemporary formulation of new assimilation theory and explain their relevance to the context of reception. Finally, while the role of religion was largely absent from assimilation theory, for post-9/11 Muslims' assimilation religion is inescapable. Using Portes \& Rumbaut (2006), I conclude the theoretical framework with a discussion of religion in the context of contemporary Muslim immigration.

\section{The Context of Reception}

Stepick \& Dutton Stepick (2009) have offered a useful and comprehensive account of the context of reception, i.e. the environment that confronts immigrants upon arrival to the host nation, which includes the ongoing attitudes, available opportunities and policies of the host society within which the second and third generation of immigrants grow up and reside. The authors depict positive, neutral and negative contexts of reception, how they vary between national, regional and local 
levels, as well as how they shift and change over time. Stepick \& Dutton Stepick (2009) describe the construct as dynamic and variable across multiple levels throughout the society. It is thus a compelling framework within which to analyze second-generation Muslim immigrants because it allows for an exploration of the construct without becoming fixed upon or preoccupied with one particular form or historical period, exhibiting what Derrida (1964) once referred to as 'play'.

The United States has repeatedly undergone an internal debate over the relative costs and benefits of immigration at different points throughout its history (Alba \& Nee, 2003). Today "there is once again a factionalizing discourse as some established residents feel the new cultural norms brought by migrants threaten their perception of the American way of life, while others welcome the diversity and accept a new cultural pluralism" (Stepick \& Dutton Stepick, 2009:2). These tensions have come to theoretically define the context of reception, determining "the opportunities available to immigrants and how immigrants are treated by members of the host society" (Ibid).

Positive, Negative and Neutral Contexts at National, Regional and Local Levels

Where immigrants encounter favorable terms such as legal status, economic opportunities, and welcoming treatment by established residents they are said to encounter a positive context of reception. The U.S. policy toward Cuban immigrants, for example, is identified by Stepick \& Dutton Stepick (2009) as 'extremely favorable' in relation to their later-arriving Nicaraguan and Haitian counterparts. Cuban immigrants 
are granted permanent residency in the U.S. after only one year. In the 1960's and 1970's, Cubans also received “a vast array of benefits that allowed [them] to quickly recertify their professional credentials and establish businesses" (Stepick \& Dutton Stepick, 2009:3).

Haitians, by contrast, have encountered "at all levels consistently negative contexts of reception" (6). According to Stepick \& Dutton Stepick (2009), U.S. coast guard ships have regularly interdicted boats headed toward the U.S. from Haiti, refused to grant asylum or refugee status, and jailed "without parole Haitians who do make it to the U.S. without a visa and claim they want to stay" (Ibid). Mexican immigration to the U.S., meanwhile, is highlighted as an example of neither positive nor negative contexts of reception. Instead, they experience a mixture of tolerance, discrimination and neglect at various levels. Contexts of reception are therefore seen as positive, negative, or ambivalent in this way, and are often highlighted as one of, if not the most important, determinants of life outcomes and trajectories of community well-being.

In addition to being identified as positive, negative or ambivalent, contexts of reception can also vary across national, regional and local levels. While legal and political debate largely occurs at the national level (seen for example in recent proposals at the national level to build a wall on the Southern border with Mexico, grant a general amnesty, deport undocumented aliens, or impose a moratorium on all immigration from Muslim-majority nations), there is also a cultural debate and associated activities over 
integration and assimilation that reaches into and impacts contexts of reception at the regional and local levels, involving both local media as well as "private discourses in the minds of individuals" (Ibid). The 'suitability' of Muslims as citizens and the 'compatibility' of Islam with Western norms are two prominent examples of such private discourses that exist not only in the national debate, but also can emerge in local interactions at such banal locations as grocery stores and schools.

At the local level, furthermore, prior research on New York and Los Angeles has highlighted the comparatively favorable effect particular geographies can create for second generation immigrants (Kasinitz, Mollenkopf \& Waters, 2004; Kasinitz et. al., 2008). Immigrants and their children currently make up more than half of the population of New York city, compared to less than a quarter for native-born whites and their children. What this has essentially meant in New York City, according to Kasinitz, Mollenkopf \& Watern (2004), is that a long history of immigration to has reshaped the local context of reception such that the traditional 'bright line' between white natives and non-white immigrants exists in a more 'blurred' form and experienced more like a continuum. In this way, local contexts can both reflect and diverge from regional and national contexts of reception.

Where policy and legal status are at stake in largely national terms, economic opportunity and social inclusion are more immediately at stake at the regional and local levels, respectively. Mexican immigrants are currently an emblematic example of this 
variation between levels in the U.S. (Portes \& Rumbaut, 2006). For example, the undocumented status of many Mexican immigrants is problematized in political terms at the national level while low-wage labor and service-sector employment opportunities remain available at local and regional levels. Thus positive, negative and ambivalent contexts of reception can align or diverge at national, regional and local levels, resulting in various forms of consonance and dissonance for various immigrant groups in the U.S. across different places and at different times - with important consequences in each case.

While most literature focuses on first generation immigrants, increasingly scholars have specifically focused on the second generation (Portes \& Rumbaut, 2001, 2006; Alba \& Nee, 2003; Roy, 2004; Nagel \& Staeheli, 2011; Sirseloudi, 2012; Voas \& Fleischmann, 2012; Abbas, 2012), for whom contexts of reception also constitute the environments into which they are socialized, and within which they construct and maintain religious meaning. When presented with a positive context of reception, "immigrants are more likely to feel a sense of belonging that incorporates the immigrants into the established residents' figurations" (Stepick \& Dutton Stepick, 2009:10). On the other hand, when presented with a negative context of reception, “marked by prejudice and discrimination, immigrants are more likely to react by constructing alternative configurations apart from those of the established residents" (Ibid). In the absence of a negative context of reception, members of the second generation can be seen to "proprietarily take their place in society for granted" (Ibid). It 
is the shock of pivotal events, however, that can force them "to reflect on their sense of belonging."

Slow Changes or Sudden Shifts?

Contexts of reception can also shift and change (Stepick \& Dutton Stepick, 2009). The passage of time across immigrant generations, the intensity of personal interactions within a given context of reception, or the occurrence of 'pivotal events' can all serve to shift contexts of reception from positive to negative, or in any other possible direction. To demonstrate this phenomenon, the authors highlight the 2001 case of Elian Gonzales as a pivotal event for Cubans in Miami, who strongly believed he should stay in the U.S., even though "non-Hispanics both inside and outside of Miami [believed] that the boy should be reunited with his father in Cuba" (Stepick \& Dutton Stepick, 2009:7). In this way the national and local contexts of reception diverged for Miami Cuban Youth, shocking them "into an awareness of their 'otherness' vis-à-vis the national social and political landscape" (8), and forcing them to reflect on their sense of belonging within the American mainstream. In the next chapter, I shall argue that 9/11 constituted a dramatic change of context of reception for Muslim immigrants to the U.S.

\section{Boundaries \& Boundary Processes}

In their extension of classical assimilation theory, Alba \& Nee (2003) have identified both formal (state) and informal (cultural) mechanisms to account for 
contemporary assimilation trends. State institutions have formally increased the cost of discrimination in the workplace and in public institutions, they argue; first by protecting the civil rights of immigrants, and second, by punishing acts of overt discrimination. Cultural mechanisms of assimilation have reduced informal racism in personal relationships and residential segregation by promoting inclusion as a value. This 'valorization of inclusion' has proven "sufficient to produce public and private policies intended to foster it within the framework of equality under the law" (280). This cultural change, Alba \& Nee (2005) argue, "is contributing to an incremental remolding of that mainstream" (Ibid). "Assimilation has reshaped the American mainstream in the past, and it will do so again, culturally, institutionally, and demographically" (282).

The process of incorporation into the mainstream basically involves "reducing perceptions of the individuals' cultural and social distance from the dominant group" (Alba \& Nee, 2003:286). As Alba (2005) has observed in subsequent research, furthermore, the boundaries immigrants cross and the processes they employ within them do not always look the same across time and place. Between Europe and the U.S., for example, Alba (2005) has distinguished between 'bright' boundaries, where "the distinction involved is unambiguous, so that individuals know at all times which side of the boundary they are on" (22) and 'blurred' boundaries, which involve "zones of selfpresentation and social representation that allow for ambiguous locations with respect to the boundary." While "blurred boundaries generally characterize the situation of Mexicans in the U.S., [...] bright boundaries characterize the European context for 
Muslim groups" (20). The nature of the boundary is particularly relevant because immigrant groups "have produced an adult second generation, socialized in the receiving society and having the potential to challenge or cross boundaries that are more or less taken for granted in the case of its immigrant parents" (21).

For the second generation, different boundary processes associated with each boundary type determine the form assimilation will take. In the case of a bright boundary, "assimilation is likely to take the form of boundary crossing and will generally be experienced by the individual as something akin to a conversion" (Alba, 2005:24). Where membership in one groups begins, in another it ends. Blurred boundaries, by contrast, "could mean that individuals are seen as simultaneously members of the groups on both sides of the boundary or that sometimes they appear to be members of one and at other times members of the other" (25). In the case of a blurred boundary, assimilation is likely to occur through selective acculturation, where immigrants employ strategies to manage both familial and public social zones of identity and belonging.

While positive and neutral contexts of reception generally allow for boundaryblurring to occur, negative contexts of reception rely on bright boundaries to clearly mark natives and immigrants apart from one another. While comparatively neutral pre9/11 contexts of reception suggest a blurred boundary once existed for Muslims in the U.S., evidenced by research on Iranian immigrants in the 1990's (Bozorgmehr, 1997; Allen \& Turner, 1996; Moghissi, 1999; Modarres, 1998; Jasso, 1997) for example, the 
shift to comparatively negative post-9/11 contexts of reception in the U.S. has also meant a concurrent shift in the nature of the perceived boundary between Muslim immigrants and non-Muslim natives from blurred to bright. What this has meant for boundary processes among the second generation, in particular, remains one of the core exploratory foci of this research.

\section{The Role of Political Identity}

To address this second development, this study emphasizes the utility of political identity within boundary processes for members of the second generation. In particular, the renewed salience of religious identity for Muslim immigrants in the U.S. suggests that religious identity serves as an important form of political identity in response to negative post-9/11 contexts of reception (Mamdani, 2002). Political identity here refers to the understanding and expression of the self in relation to one's perspective and perceived individual/group self-interest. The construction and maintenance of religious meaning among members of the second generation thus serves as the primary lens of analysis for political identity in this context.

Mamdani (2002) observes that 9/11 "has turned religious experience into a political category" (765). By politicizing Islam in relation to the West, Mamdani (2002) argues that we have come to view the 'clash of civilizations' between 'Islam and the West' as a fundamentally cultural conflict. The problem with 'culture talk' - the idea that political differences are fundamentally rooted in cultural and religious beliefs, 
according to Mamdani (2002), is that it dehistoricizes political identities in order to essentialize them. In other words: terrorism that claims Islamic motivation is interpreted by those in the West as a reflection of Islamic culture and politics. It follows, then, among those who accept this logic in taking such a view (e.g. Huntington but also many others) that Islam is culturally opposed and antithetical to Western culture and thus, the two are intrinsically opposed and necessarily conflictual.

While this explains the rhetoric of both radical Islam and Islamophobia, the logic is fundamentally flawed in its assumption of two independent, opposed civilizations. Mamdani (2002) argues compellingly on this point that, historically speaking, Islam and the West "are born of an encounter, and neither can be understood in isolation, outside of the history of that encounter" (767). If Western political power is representative of Western culture, the logic of culture talk goes, then its politics must be a reflection of its true nature, it's 'real self'. Thus, it can be judged accordingly. But of course, anyone familiar with the complex fractures and contradictory impulses at the heart of any politics, much less Western politics, can also understand the gross simplicity of this kind of essentialism. In order to avoid the myriad reductions of culture talk, we must "question the very tendency to read Islamist politics as an effect of Islamic civilization whether good or bad - and Western power as an effect of Western civilization" (Mamdani, 2002:767). Reducing complex realities into simplistic frames of 'good' and 'bad' achieves only two things: first, it uproots them from historical reality - to which 
contemporary reality is often tethered; and second, it fuels contemporary distortions that continually misidentify problems and their solutions.

Thus, culture talk is only possible if we forget history. And Mamdani's (2002) observation that culture talk dehistoricizes political identities recognizes this 'historical forgetfulness' on both sides of the conflict between 'Islam and the West'. Despite the fallacies and historical anachronisms of 'culture talk', however, political identities remain the primary vehicle for speech and action within post-9/11 contexts of reception. And in this sense Islamic terrorism, according to Mamdani (2002), is a 'modern construction' at the service of a 'modern political project'. "The distinction between political terror and crime is that the former makes an open claim for support" (773). Terrorists "have a cause and a need to be heard [...]" (Ibid). Thus, "the only way to isolate individual terrorists is to do so politically, by addressing the issues in which terrorists 'wrap themselves up'." Political and religious identity have, therefore, are importantly wrapped up in each other.

Viewing immigrants' religion through the lens of political identity is not a recent innovation, either. Alba \& Nee (2003) discuss the historical salience of religious identity in relation to European Jews and Catholics during $20^{\text {th }}$ century U.S. immigration, for example, but do not specifically address Muslims. Similarly, while Alba's (2005) comparative study of second-generation immigrants examines Muslims in Europe and Mexicans in the U.S., it does not examine the comparative aspects of religion and 
ethnicity as principles of group organization in relation to political identity. And while Portes \& Rumbaut (2006) provide an incisive account alluding to the effects of $9 / 11$ as a pivotal event, and set this accounting against a broader discussion of Islam within U.S. immigration history, they do not specifically focus on the second generation of immigrants in this regard, nor do they focus on the assimilative tendencies of upwardly mobile Muslim immigrant groups in the U.S. and the attendant relevance of boundary processes toward this end. Thus, while immigration scholars have consistently observed the historical intersection between immigrants' religious and political identities, they have also consistently pointed to the renewed contemporary salience of this intersection for Muslim immigrants in the post-9/11 era. This research simply makes the connection between religious and political identity explicit in this context, and proceeds according to the vision of potential problematics already identified throughout the broader immigration research literature.

\section{The Role of Religion: Linear vs. Reactive Identity}

Portes \& Rumbaut (2006) offer the final component of the theoretical framework offered here in their analysis of the "role of religion in the development of ethnic communities and the reassertion of national cultures and language" (p.311). Of the 'three Rs' that define the function of religion for immigrants the first two, 'respect' and 'resources', are key factors in strengthening ethnic communities and facilitating upward mobility where "channels of communication between the two generations 
remain open, strengthening beliefs and norms antithetical to downward assimilation" (p.323). When religion acts as a source of 'refuge', the third function Portes \& Rumbaut (2006) identify, it can help mitigate the effects of social and economic barriers erected by the host society against immigrants and their communities, but it can also represent a space where "religion becomes reactive, signaling a break from the past" (p.332).

Reactive religiosity, the authors note, "compromises selective acculturation when it is pitted against the beliefs and norms of parents, although it may offer to some the chance to find the meaning and direction that, for some reason, they do not find at home" (p.336). Here religion is constructed to meet individual needs on an individual's terms, often in response to traumatic encounters with social and economic discrimination. Where religion does not become reactive, it remains linear, according to Portes \& Rumbaut (2006). Here parents and children continue to adhere to the religion of their forebears, "reaffirming traditional beliefs as a source of comfort and protection" (326).

Previous studies of immigrant religion lead us to expect that for second generation Muslim immigrants it might provide respect and resources. But the fundamental transformation of the context of reception for Muslim immigrants, detailed above, might lead us to expect that Muslim immigrants could find refuge and adopt a reactive religiosity. Moreover, the politicization of Islam, especially prevalent since $9 / 11$, adds a dimension to religion not envisioned by Portes and Rumbaut (2006). 
Understanding the construction and maintenance of Islamic religious meaning therefore requires that we look beyond the immigration literature to contemporary scholarship on Islam itself.

\section{Globalization \& Pluralized Religious Authority in Islam}

The politics of Islamic terrorism continue to be expressed by terrorist groups, and their agents, in expressly religious terms. Their claims for support, meanwhile, are consistently defined by claims to Islamic normativity in the global public sphere. This is problematic for a number of reasons - to a lesser extent because it confounds the separation between the political and religious that defines many contemporary analyses, but most of all because religious authority has always been pluralized in the Muslim world - i.e. it has always existed in a political context of its own making.

It is important to consider that "there has never existed a situated, singular source of authentic Muslim knowledge... globalization can be seen to represent a further shift in the extent and intensity of debate about the meaning and nature of the authoritative in Islam" (Mandaville, 2007:102). Unlike the Catholic Church where the Pope is an ultimate authority, Islam is more like Protestantism in that there is no single authority to determine religious disputes. Instead, there are different schools of Islamic jurisprudence, known as fiq, which guide a pluralized religious authority that is diffuse and local in its manifestations (Mandaville, 2007). Hence, religious authority does exist, 
but there is no clearly and universally-sanctioned centralized authority figure. Thus, pluralized religious authority in the Muslim world has always been politically 'at play'.

In a system where religious authority has always been pluralized in this way, and now on a truly global scale, discussions about what Islam is and is not are not so clear cut. As Mandaville (2007) observes: "claims and pronouncements as to what Islam is and is not tend to function simultaneously as statements of geopolitical and geocultural affiliation [...] An appreciation of how geopolitics mediates the intense politicization of almost any public claim to Islamic normativity is hence central to understanding the complex plurality of authority in the Muslim world today" (112-113).

Simply put, because religious authority has always been pluralized in the Muslim world, and because pronouncements as to what 'is' or 'is not' Islamic are simultaneously statements of geopolitical and geocultural affiliation, I argue that simple claims to Islamic normativity in the global public sphere are themselves sufficient to categorize a given event or phenomena as 'Islamic' because of the resultant inability of any other person to credibly or authoritatively say otherwise in the scholarly sense. In other words, because Islamic terrorism has been consistently defined by claims to Islamic normativity in the global public sphere, the political issues and claims for support in which terrorists 'wrap themselves up' must also be understood in religious terms. In this way, contemporary constructions of Islam can also be seen as constructions of political 
identity, distinguished primarily by the form and nature of historical consciousness they employ.

There appear to be two main variants of Islam that can be identified in this regard: 'Globalized Islam' (Roy, 2004) and what I have termed 'Localized Islam'. Mamdani (2002) observes that "Islam is today the banner for diverse and contradictory political projects. It is not only anti-imperialist Islamist movements but also imperialist projects, not only demands to extend participation in public life but also dictatorial agendas, which carry the banner of Islam. The minimum prerequisite for political action today must be the ability to tell one from the other" (774). In order to do just that, to 'tell one from the other' for the purposes of this research, this distinction between Globalized Islam and Localized Islam will serve as the basis for the analysis of political identities among Second-generation Muslim immigrants in this study.

\section{Localized Islam}

Localized Islam appears to manifest according to two distinct but related forms

of historical consciousness. The first involves the ongoing and creative construction of Islam within contemporary geographical and cultural contexts. This can be both apolitical, where diverse communities emphasize the aspects of Islam that are particularly meaningful to them for one reason or another, or political, where Islam is constructed in response to locally-dominant media portrayals, contemporary discourses and social interactions that have themselves politicized Islam in one way or another. In 
either case, the construction and maintenance of religious meaning is said to be 'localized' because its roots lie in a particular geography or culture of the past or present.

Research on the role of mosques in the acculturation process for Muslim immigrant women, for example, emphasizes the unique functions of 'conservative' and 'liberal' mosques in meeting the needs of different immigrant generations (Ozyurt, 2010). 'Conservative' Mosques are seen to embody 'separatist cultures' "whose primary goal is to preserve the identity and culture of "back home"' for first-generation Muslim immigrants (302). Liberal, or 'futuristic', Mosques with 'integrationist cultures' are seen to facilitate "the integration of the Muslim community in the United States and the creation of a new American-Muslim identity" (305) for second and third-generation Muslim immigrants. In this case it becomes relatively clear that Muslim immigrant communities with different generational compositions actively seek, create and rely on different institutions - and distinctly different visions of Islam - to fulfill fundamentally different needs.

In a more political manner, Muslims living within post-9/11 contexts of reception "are asked to explain who they are, what they believe in and what they stand for... they have to manage their Islamic identity in host countries that often portray Muslims negatively and define Islam as a religion of violence" (Yildiz \& Verkuyten, 2012:360). In this context, Muslim organizations in the Netherlands and Germany "publicly define a 
morally acceptable identity by arguing 'what we are not'" (359). Islam, and by extension Muslim immigrants, present themselves as compatible with both democracy and the host nation. The Fetullah Gulen movement established in the 1960's, for example, "focuses on the universal ethic of love, serving others and peaceful co-existence... [r]ather than the five pillars of Islam" (364), and has been offered as a response to public challenges to Muslim identity and negative stereotypes equating Islam with violence. Yukleyen \& Yurdakul (2011) argue importantly that "the variety of attitudes and approaches to integration by Islamic organisations indicate that Islam itself as a set of abstract principles is neither an obstacle nor an encouragement to the integration of Muslim immigrants. The organizations themselves set the tone..." (80)

The second form of localization involves Islam's construction and articulation within the history of specific geographies and cultures of the past, usually associated with a particular ethnicity. "Of course, by definition Islam is universal, but after the time of the Prophet and his companions (the Salaf) it has always been embedded in given cultures" (Roy, 2004:25). The cultures within which Islam has been historically embedded span across Indonesia and the Indian subcontinent to the Middle East and North Africa. "Islam looks very different in each of these regions because as the religion spread it adopted the customs and traditions of the people of various lands" (Kumar, 2010:8). Sufism, Shiism, Sunni Islam are as distinct from one another as are the myriad cultures and ethnicities that construct and shape the practice of Islam within them. The idea of a universally-essentialized and monolithic Islam becomes increasingly difficult to 
account for, "given the diversity of Islamic practices that run the gamut from secular democracies (such as Indonesia) to dictatorships (such as Saudi Arabia)" (Ibid). The vast majority of Muslims throughout the Islamic world and its diaspora, where they are integrating within their host nations, appear to construct and understand Islam in a localized manner (Gest, 2012; Wike \& Grim, 2010).

\section{Globalized Islam}

The phenomenon of globalization, according to Roy (2004), has provided a "good opportunity to dissociate Islam from any given culture and to provide a model that could work beyond any culture" (25). 'Deculturation' refers to the process that involves such a decoupling of religion and culture, leaving a globalized Islam purged of local and cultural content. Roy (2004) specifically refers to Islamic fundamentalism as a 'tool of deculturation'. Sadowski (2006) agrees: "fundamentalist groups share a mission that can be both revolutionary and reactionary: They seek to purge Islam of local or nonMuslim practices that may have crept in over the centuries and to return it to the pure practice of the faith that prevailed during the life of the Prophet" (220). The form of historical consciousness that emerges here is preoccupied with an idealization of one particular historical period, not a particular locality or culture in the past or present.

What makes fundamentalist Islam eventually constitute a 'globalized Islam', then, is the Islamist conviction that "lay Muslims, people with experience in the world and not just holy texts, also have a voice in the interpretation of the faith and the 
construction of its political institutions" (Sadowski, 2006:221). The preoccupation with a particular view of one historical period, while implicitly global, ironically requires globalized flows of information and informal interpersonal linkages rooted in the contemporary period to become globally coherent and collectively free their voices to make authoritative claims to Islamic normativity in the global public sphere. Globalized Islam is, in this manner, a thoroughly modern construction as Mamdani (2002) insists.

It has not been until the advent of the internet, in the form of a truly globalized communications infrastructure, that pluralized religious authority across the Islamic world and its diaspora achieved such a level of coherence and coordination. And as Cesari (2009) observes: "any comprehensive understanding of Muslim minorities needs to take the phenomenon of global Islam into account" where "technological developments are affecting Islamic discourse and breaking up the monopoly of traditional religious authorities on spiritual issues" (162). Amidst myriad forms of Localized Islam within individual communities and throughout the world also exists a globalized vision that purports to speak for all Muslims - for Islam itself, preoccupied with a return to the historical reality of $7^{\text {th }}$ century Arabia.

"Within this broad [globalized] market of ideas and interpretations, there is now a global source for Islamic thought, resulting in an exponential increase of Islamic authority figures... Virtual Islam is part of this second form of transnational Islam. 'Electronic religiosity is causing Islam to expand globally via the circulation of 
audio and videotapes, the broadcast of independent television satellite shows, and, most significantly, the creation of websites. Bulletin boards, chatrooms, and discussion forums on the internet are promoting alternative and even contradictory understandings of Islam where monolithic, national interpretations previously existed"' (Cesari, 2009:167)

In her discussion of 'virtual Islam', Cesari (2009) also makes an important distinction between fundamentalism and radicalism. The construction of a Globalized Islam does not necessarily lead to radicalization - that is another step on its own. But their views fit with one another on several key grounds. "They make absolute claims to the truth, they demand blind obedience, they idealize one particular period of history, they claim that their ends justify any means, and they deploy a formal concept of holy war (Kimball, 2011; Stern, 2003). But these doctrines do not cause people to be terrorists; rather, potential terrorists seem to select or construct these types of doctrines" (Sadowski, 2006:232). In other words, not all who construct and practice a Globalized Islam are terrorists, but the vast majority of terrorists appear to practice and construct a Globalized Islam and eschew its localized manifestations.

In summary, this theoretical framework has outlined the way in which diverse contexts of reception connect with and inform different types of immigrant-native boundaries and their associated boundary processes. The role of politically-salient religious identities has also been highlighted as the primary vehicle Muslim immigrants 
use to navigate through these processes within post-9/11 contexts of reception. Finally, it has described the construction of linear and reactive religious identities and their consequences, illustrating how they have been linked in the research literature to different contexts of reception and boundary processes. In the model below, positive and ambivalent contexts of reception are shown to be associated predominantly with blurred boundaries, selective acculturation processes and linear religious identities. The relationship between negative contexts of reception, bright boundaries and reactive identity formation is much more straightforward and entails much less variability.

Integrated Analytical Model

1) Context of Reception:

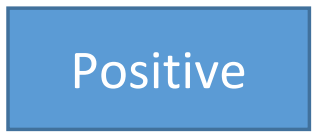

2) Boundary \& Process:

3) Religious Identity:

Figure 1.

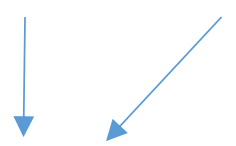

Blurred

Boundary

\section{Ambivalen}

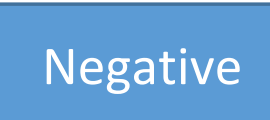

\&

Selective

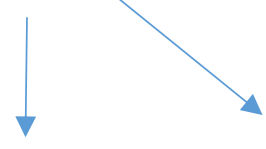

Linear

Religious

Identity
Reactive

Religious

Identity
Bright

Boundary

\&

Boundarv
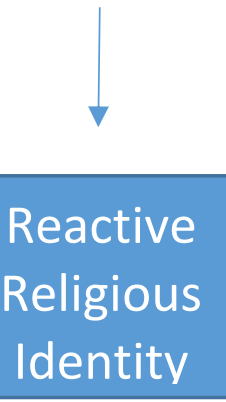


\section{Chapter 3}

\section{Literature Review}

\section{The Effects of Post-9/11 Contexts of Reception in the U.S. and Europe}

There are significant differences between Muslim immigration to the U.S. and Europe that are, in turn, reflected in their respective research literatures on the second generation. Historically, large-scale Muslim immigration to Europe was established via temporary post-WWII guest-worker programs which eventually became permanent, paving the way for a flow of Muslim immigration that gradually "crowd[ed] into small homogenous nations" (Leiken, 2005:122). In the U.S., Muslims immigrated in a comparatively gradual manner - one that was also geographically diffuse and ethnicallyfragmented within a nation itself built on immigration (Ibid). For this reason, the European research literature has focused more straightforwardly on the religion of Muslim immigrants, while research in the U.S. has primarily focused on their ethnicities or countries of origin -reflecting Alba's (2005) critical finding concerning the role of respectively bright and blurred boundaries in each context.

\section{Research on the Second Generation in Europe}

This review separates the European research literature on second generation Muslim immigrants into three basic categories: 1) economic achievement \& educational 
attainment as markers of structural integration, 2) cultural integration and social barriers and 3) religiosity. Each category can be seen to reflect the distinctly European research context, moreover. Studies focusing on economic achievement and educational attainment of the second generation, for example, are often conducted within cross-national frameworks comparing the UK, France, Germany, Belgium and the Netherlands and their respective Bangladeshi, Maghrebian, Turkish and Moroccan Muslim populations. Crul \& Vermeulen (2003) were among the first to observe that "the oldest children born to postwar immigrants on European soil have recently entered the job market" (965) and can now be studied as a group according to their educational and economic performance, which they undertake through comparative analyses of differences immigrant groups and national contexts. Others, such as Algan et. al. (2009), have conducted comparative education and employment analyses of Muslim immigrant groups across both national contexts and first/second generations. Beyond cross-national analyses, other scholars have compared the economic and educational performance of different Muslim immigrant groups within the same country (Timmerman, Vanderwaeren \& Crul, 2003; Silberman, Alba \& Fournier, 2007).

These studies have consistently found lower educational and economic outcomes among Muslim immigrants, and the second generation in particular, to be the case: "a Muslim candidate is 2.5 times less likely to receive a job interview callback than his or her Christian counterpart... [while] second-generation Muslim households in France have lower income compared with matched Christian households" (Adida, Laitin 
\& Valfort, 2007:22384). These differences have been attributed by scholars to barriers rooted in Islamophobia and anti-Muslim discrimination. While Silberman, Alba \& Fournier (2007) also find that "Muslims are substantially, if not severely, disadvantaged" they also add that: "they believe they have suffered from discrimination in the hiring process and their reports have strong plausibility" (1). In the midst of this discrimination forcing the second generation into lower segments of the labor market Timmerman, Vanderwaeren \& Crul (2003) also observe that "Islamism can provide a transparent, supportive, and all-embracing frame of reference" (1065) in response.

Secondly, European research on cultural integration pointedly reflects Alba's (2005) findings concerning the role of bright boundaries for the second generation. These studies have focused on public discourses surrounding social discrimination and tolerance toward Muslim immigrants, honor-killings, the hijab, sharia law and the construction of mosques in ways that conspicuously reinforce bright boundaries. In their examination of the cultural integration of Muslim immigrants, for example, Bisin et. Al. (2008) compared national survey data of ethnic minorities in the UK to determine that "Muslims integrate less and more slowly than non-Muslims" (445). At the same time, research using survey data from Germany indicated that "individuals with strong religious commitments are less likely than secular individuals to hold egalitarian gender role attitudes" (Diehl, Koenig \& Ruckdeschel, 2009:278). These differences essentially reflect and duplicate debates over cultural values that "reinforce existing bright 
boundaries, or a strong sense of us versus them, between immigrants from Muslim and/or Turkish backgrounds and the majority population" (Korteweg \& Yurdakul, 2009).

Lastly, the concept of religiosity has been used as a lens through which the conception and practice of Islam among Muslim immigrants has been measured, and also through which the integration of Muslim immigrants has been understood especially in connection with intergenerational and cross-national analyses of structural integration. Fleischmann and Phalet (2012), for instance, have tested hypotheses concerning whether "an inverse relationship between structural integration and religiosity" (320) can be predicted by secularization - measured at an institutional policy level across four European capital cities. Similarly, Connor (2009) has explored levels of religiosity according to comparatively negative or positive 'contexts of immigrant receptivity' and found that "less welcoming immigrant contexts are associated with higher religious outcomes among Muslim immigrants in comparison to the host region's religiosity" (376). In each of these cases, it becomes clear that studies of Muslim immigrant religiosity fundamentally reflect the assumptions of the host nations in which they are conducted, feeding back into discourses on discrimination by and against Muslim immigrants and the maintenance of bright boundaries reinforcing a prevailing 'us versus them' mentality in the European context.

The measurement of religiosity, it must also be said, has also been subjected to substantial critique: 
"To study the religiosity of Muslims by focusing, as many studies do, on conspicuously visible, vocal and devout practitioners is to risk reinforcing public understandings of Muslims as particularly (and dangerously) religious' (Schmidt, 2011, p.1217) on the one hand, and reproducing the 'ideological aspiration of Islamist and Islamic revivalist movements' on the other, with their 'privileging of Islam as the supreme guideline of all fields of life' (Schielke, 2010, p.2)" (Brubaker, 2012:6).

Brubaker's (2012) argument is compelling on several grounds. First, it highlights the unforeseen effects and unintended consequences of using 'religiosity' as a category of analysis - with respect to both public perceptions of Muslim immigrants as well as the political aspirations of Islamist ideologues and radical recruitment efforts in the West. Second, and more importantly, it reflects the tendency of researchers to conduct analyses of Muslim immigrants that are rooted in the assumptions of their own culture and religious heritage. And unlike the research literature on cultural integration, which can also reflect culturally-rooted assumptions of the host nation, critiquing religiosity appears to be a much more theoretically-based endeavor.

Thus, the European research literature can be seen to reflect a continuum between empirical accounts of structural integration for the second generation that tend to avoid or otherwise circumnavigate the normative, theory-laden issues defining bright boundaries for Muslims in Europe and research efforts that engage more directly 
with political conflicts and religio-cultural differences between Muslim immigrants and European natives. The danger, in this sense, is twofold: between the cold vacuum of statistical abstraction and the partial blindness that comes from staring perpetually at the sun. There does not appear to be a clear path in between, moreover, yet it has been walked with encouraging degrees of success by scholars committed to exploring the European context.

In summary, the European research literature reflects one of Alba's (2005) primary findings: that bright boundaries not only exist, but are also highly salient among the broader public and thus deeply consequential for second-generation Muslim immigrants. Research on economic and educational attainment frequently highlights the role of structural barriers and discrimination, indicating Muslims in Europe are possibly experiencing segmented assimilation (Stepick \& Dutton Stepick, 2010). Research on cultural integration and religiosity, furthermore, has highlighted the degree to which bright boundaries between Muslim immigrants and the native majority can retard integration and exacerbate already confusing discourses around religious and cultural values. In Europe, where Muslims are also the largest single-ethnicity immigrant minority populations in each nation, the effects of post-9/11 contexts of reception have not boded well for structural integration of their communities. Cultural integration also remains a primary object of concern for European publics in this context. In Alexander's (2013) words, the debate in Europe "is not over whether immigrants should be incorporated, but over the grounds for doing so" (531). 


\section{Research on Second-Generation Muslim Immigrants in the U.S.}

The sociological research literature on the Muslim second generation in the U.S. is comparatively sparse relative to Europe, and even then only partial and indirect in its focus on the second generation. Research on economic achievement and educational attainment focuses largely on specific ethnic groups, such as Lebanese and Somali immigrants (Ajrouch \& Kusow, 2007; Ajrouch \& Jamal, 2007) that often entail subsets of atheists, Christians and Muslims within them. Cainkar's (2004) analysis of Islamic revivalism among second-generation Arab-American Muslims is perhaps the most specific example of research focusing on second generation Muslim Americans. While it omits non-Arabs, most notably Iranian-Americans, it engages specifically with the research literature in identifying religion as a critical explanatory factor and addresses the position of second generation Muslim Arab-Americans at the crossroads of globalization and local sociopolitical environments.

Cainkar's (2004) work focuses on Islamic revivalism in the historical context of U.S. Muslims and not specifically on the impact of post-9/11 contexts of reception on second-generation immigrant Muslims in the U.S. This represents a deviation from much of the U.S. and European research literature on second generation Muslims. The author is explicit on this point, citing a footnote in Roy's (2004) Globalized Islam in which it is considered "increasingly irrelevant to study Islam in the West through the prism of immigration" (8). With a word of agreement, the author turns her focus away from 
immigration and toward religiosity, where "intensely personal experiences" (Cainkar, 2004:103) can be better explored at the individual level through ethnographic analysis and 'oral history research' (in this particular case within the Chicago Metropolitan area). This justification is perplexing, however, when considering the context of Roy's (2004) footnote: it calls for a religious anthropology of Islam to develop in the European context, where Muslim immigrants are also often the single largest geographicallysegregated and ethnically-homogenous minority groups in host nations. His preceding discussion on the matter focuses specifically on Western Europe, and on the city of Paris in particular. Applying Roy's (2004) comment to the U.S. context involves eliding this important difference. This research holds, by contrast, that the transatlantic divide is crucial for understanding the relevance of immigration for developing an anthropology of Islam in the U.S. context.

In the U.S., the character of Muslim immigration is fundamentally different (not to mention the character of immigration generally). Here Muslim immigration has been as ethnically-diverse as it has been geographically diffuse, casting legitimate doubt on the purported 'irrelevance' of immigration as analytical lens for American Islam. Cainkar's (2004) concluding predictions: that "knowledge of American methods of organizing will increase Muslim civic political integration in American society..." (118) and that "the complex dialectic between Islam and the West will continue to unfold as Islam becomes institutionally and socially acknowledged as an American religion," are thus vague and largely generalized. In this research, the turn toward religiosity and 
away from immigration appears to have been a fateful decision - one which has privileged domestic historical and contemporary political discourses over the eminently consequential forces of globalization and transnational connectivity in its analysis of Islamic revivalism. This research has deliberately avoided such an approach in the interest of maintaining a genuinely exploratory focus and avoiding its attendant scholarly liabilities.

Despite the comparatively minimal attention paid toward second-generation Muslim immigrants in the U.S. relative to their European counterparts, research in the U.S. has focused on several aspects of post- $9 / 11$ contexts of reception that remain relevant for the second generation today. Vidino (2004), for example, highlights the visibility of jihadist networks "which were virtually ignored before 9/11" (6). The impact of 9/11 in the U.S. thus also catapulted Muslim immigrants into the public sphere by mere association, and into public debate as public figures, auguring what Gole (2011) has referred to as the "tumultuous transition of Muslims from the status of the invisible migrant-worker to that of visible Muslim citizenship" (383). Finally, Naber (2006) has documented the incorporation of this disproportionate visibility into the domestic discourses of traditionally marginalized groups in the U.S., with particular attention paid to race and gender.

A second line of research has focused on gender, and second generation Muslim immigrant women in particular, to address the second generation in conjunction with 
contemporary discourses on women's rights in the context of Muslim immigration. Ali (2005), for example, explores the use of the hijab among second generation Muslim women. His research explores both the Quranic understanding and social reasoning used by different women wearing the hijab, as well as how shifts in religious dress may also indicate shifts in religious practice among them. Similar research by Williams \& Vashi (2007) explores the use of the hijab among second generation Muslim-American women as a tool in the creation of autonomous spaces where they navigate between social and (largely familial) religious spaces.

These works, among many others focusing on Muslim women in the U.S. context, touch on a broader strand of research literature in the U.S. that has extended Dubois' conception of 'double consciousness' to include immigrant experiences. The 'two worlds' effect brought on by demarcations between languages and cultures, between the inner world of family and the larger world of the host society, have been articulated compellingly within feminist tradition in sociology:

"For a people who are neither Spanish nor live in a country in which Spanish if the first language; for a people who live in a country in which English is the reigning tongue but are not Anglo; for a people who cannot identify with standard (formal, Castillian) Spanish nor standard English, what recourse is left to them but to create their own language? A language which they can connect their identity to, one capable of communicating the realities and values true to 
themselves - a language with terms that are neither espanol ni ingles, but both. We speak a patois, a forked tongue, a variation of two languages." (Anzaldua, 1987:35-36)

Muslim immigrant women today have come to speak a patois of their own. And it is within the heritage of this research literature that the 'forked tongue' of their lived realities and expressed values have been communicated and researched in the contemporary U.S. context. While they have found a considerable diversity of literary expression, research focusing exclusively on Muslim immigrant women in the U.S. has also been used to examine the role of Mosques in the acculturation process (Ozyurt, 2010). While members of the first generation were seen to use Mosques to recreate the culture of 'back home', second generation Muslim women were more predominantly involved in establishing "immigrant mosques whose administrators and religious leaders have a futuristic and integrationist conception of Islam... [and] are more successful in building bridges between their congregants and the larger society in general" (Ozyurt, 2010:295).

In summary, research on Muslims in the U.S. has tended so far to focus within specific ethnic groups that include non-Muslims, within religious categories such as 'Muslim' that include multiple generations, or among second generation Muslim immigrant women to the exclusion of men. Furthermore, while issues of structural and cultural integration are substantively addressed, akin to the European literature, the 
focus on the Muslim second generation in the U.S. context has remained only partial and indirect. There is thus a gap in the U.S. research literature regarding second generation Muslim immigrants within post-9/11 contexts of reception - one that might connect importantly with the European research literature while also reflecting the nature of the U.S. context.

The importance of addressing this gap, beyond the intersection occupied by second generation Muslim immigrants between islamophobia and radicalization, is further evidenced by research on public attitudes toward Muslims in both Europe and the U.S. Using survey data from 30 countries in Europe, Strabac \& Listhaug (2007) conclude that "Muslims in Europe were particularly prone to becoming targets of prejudice, even before the attacks of September $11^{\prime \prime}(268)$. At the same time, research employing social distance scales in the U.S., has found that while "Arabs reaped a 75\% positive response for marrying into one's family, with Muslims collecting a 68\% similar response in the responses gathered prior to 9/11" (Parillo \& Donoghue, 2005:264), results collected after September 11 "produced results tempered by the tragic events of that day" ranking Muslims and Arabs at the bottom of the scale, at a reported social distance greater than any other group.

In this way, the European research literature more accurately reflects the bright boundaries that exist between Muslim immigrants and native non-Muslims in Europe. These attitudes are salient in the U.S. as well, as recent research shows, but Muslim 
immigrants are not often researched directly as a contiguous group the way they are in Europe, in the very real context of their own bright boundary. Thus, while negative public attitudes and bright boundaries for Muslim immigrants are consistently observed across European and American contexts, as a consistent consequence of post-9/11 contexts of reception for the second generation, the direct identification and exploration of Muslim immigrants on these terms has occurred primarily in Europe. This imbalance in research literatures on Muslim immigrants across the Atlantic divide highlights the importance of addressing the research gap identified above.

\section{Islamic Religious Identity Across Europe and the U.S.}

While the contemporary body of research literature spanning Europe and the U.S. illustrates the construction of both Localized and Globalized Islams among the second generation, it also highlights the role of family as a significant factor influencing boundary processes for Second-generation immigrants. The following review suggests that, by all accounts, localized constructions of Islam account for the vast majority of Muslims in the U.S. and in Europe, representing what Portes \& Rumbaut (2001) refer to as 'linear ethnicity'. A small but significant minority, however, are seen to construct a Globalized Islam in response to identity crises brought on by family conflicts and social and economic discrimination, representing what Portes \& Rumbaut (2006) refer to as 'reactive ethnicity', and what I refer to more broadly as 'reactive identity'.

Selective Acculturation: The Role of Family and Society 
Foner (1997) has emphasized the impact of structural constraints (social and economic barriers) in shaping "the kinds of family arrangements, roles, and orientations that emerge among [immigrants in the U.S.]" (962). Similarly, Portes \& Rumbaut (2006) identify social and economic discrimination as one of the major determinants of downward assimilation for immigrant groups. Muslims are, however, the lowest performing group in their 'mean downward assimilation index' (320), i.e. that they are the least likely to be downwardly mobile. Portes \& Rumbaut (2006) observe that "unlike the impoverished Muslim population in Great Britain and continental Europe, American Muslims have done rather well economically. According to Baghy, the average mosquegoer in the United States is a married man with children who has a bachelor's degree or higher and earns about $\$ 74,000$ a year" (338).

Given that Muslims are not comparatively disadvantaged by structural constraints relative to other immigrant groups, the idea that "immigrants are not passive individuals who are acted upon by external forces. They play an active role in reconstructing and redefining family life" (Foner, 1997:962) may hold greater relevance for Muslim immigrants in the U.S. context. In this environment, the dynamic of intergenerational conflict presents an opportunity for the younger generation (and women in particular) to "challenge certain aspects of traditional family systems while they also try to retain others" (Ibid). 
Between the cultures immigrants bring with them - informed increasingly by transnational premigration frameworks and the post-9/11 contexts of reception that confront them in the U.S., the inner world of family becomes a place where there is a "dynamic interplay between structure, culture, and agency" (957) Thus, family and society constitute two sites where processes of selective acculturation play out for immigrants in the U.S. Islamic religious identity can also be seen as a vehicle that allows immigrants to navigate between these two sites within processes of selective acculturation. With respect to religious identity, therefore, the key question is "whether or not religion can play a major role for immigrants and the second generation as a bridge to inclusion in the new society" (Foner \& Alba, 2008).

Localized Islam in the U.S.

Because Muslim immigrant populations in the U.S. are both ethnically diverse and geographically diffuse, the current research literature has touched on the construction and maintenance of religious meaning among them in myriad ways. Studies focusing on the construction and maintenance of religious meaning in this context have primarily explored the intersection between religion and post-9/11 politics. Cainkar (2004), Duderija (2007) and Peek (2005) have specifically focused on the Muslim second generation and found that $9 / 11$ not only reinforced the salience of Islamic religious identity within domestic political discourses, but also led to the 
development of various Islamic revivalisms serving as the bases for various associations and solidarities to emerge among them.

Other researchers, meanwhile, have focused on specific Muslim-majority ethnic groups at similar intersections of religious and political identities. Ajrouch \& Kusow (2007), for example, found that Somali immigrants must deal with the dual challenges of race and religion in identity construction, while Lebanese immigrants are able to focus solely on the challenges of religious identity, facilitated importantly "by virtue of their white racial status" (72). Similarly, Naber $(2005 ; 2006)$ has researched the cultural and psychological impacts of 9/11 on Arab Immigrants in the San Francisco area and found that, consistent with other research emphasizing the renewed salience of Islamic religious identity, public Muslim identities have been employed increasingly as an effective strategy by the second generation within domestic political discourses on both race and gender. What has emerged in the U.S. research literature, therefore, has been both a recognition of the renewed salience of Islamic religious identity in response to 9/11 as well as the diverse polyvalence of localized Islams in the construction of politically-salient religious identities.

\section{Globalized Islam among Immigrants in the U.S. and Europe}

The construction of Globalized Islam appears to be almost entirely reactive in character. Reactive identity formation, Portes \& Rumbaut (2006) note, "compromises selective acculturation when it is pitted against the beliefs and norms of parents, 
although it may offer to some the chance to find the meaning and direction that, for some reason, they do not find at home" (p.336). For a small minority, family conflicts meant to control and ensure upward mobility for the second generation lead instead to a break with the traditions and trajectories of the first generation. "As a result, the young are forced to seek alternative forms of 'empowerment knowledge', whether it is via the Internet, underground reading groups or religious study circles (Bunt, 2003). This knowledge is generally loaded with a radicalising message that promotes intolerance, antipathy and the often disregard of all things Western - evolved in the context of resistance politics of the oppressed and disempowered" (Abbas, 2012:350).

Scholars observe this pattern to also occur in response to perceived social prejudice and marginalization among a small minority of second-generation Muslims. "Second-generation Muslims may still react to perceived discrimination and lack of mobility opportunities by embracing the preachings of radicalized imams. This trend has been exemplified by the repeated presence of second-generation Muslims in terrorist attacks in Great Britain, France, and the United States" (Portes \& Rumbaut, 2006:343). Sirseloudi (2012) agrees: "The more young Muslims (irrespective of their ethnic origin) identify with the global Ummah, rather than with either the country of origin of their parents or Germany, the more open they become to all kinds of Islamist streams" (p.818). 
Where scholars observe the role of a culturally-rooted, flexible and localized Islam to strengthen immigrant communities and aid upward mobility, they observe its reactive construction to have the opposite effect. A globalized Islam purged of local and cultural content, which is generally ideological and preoccupied with a 'pristine past', actively opposes assimilation into the mainstream host culture. According to Sirseloudi (2012), it is this "separation of culture and religion, [that] has a radicalising effect when combined with experiences of discrimination and low opportunity for integration" (Ibid). Family conflicts can leave second-generation Muslims "seeking a 'purer' form of Islam than that practiced by their parents" (Nagel \& Staeheli, 2011:441). Voas \& Fleischmann (2012) also find that “immigrant parents are surprised by their children's rejection of some traditions as non-Islamic and their determination to return to a 'real Islam'" (p.534). Efforts by the second generation to "appropriate an Islam that is separate from the ethnic culture of the parental generation" (Ibid) is a consistent theme documented by scholars among the Muslim second generation as an active response to both family conflicts with parents, as well as perceived discrimination and social marginalization.

\section{Research Hypothesis}

This research was initially driven by the observation that the shift to negative post-9/11 contexts of reception and the emergence of newly bright boundaries had increased the quantity and severity of discrimination experienced by second-generation Muslim immigrants. In response, it was hypothesized that the research interviews 
would encounter and reflect accounts of both Localized and Globalized Islams, placing the focus of subsequent analysis on the consequences of Globalized Islam among the second generation and the various factors associated with its emergence. 


\section{Chapter 4}

\section{Research Methods}

This exploratory study aims to illuminate the intersection occupied secondgeneration Muslim immigrants within post-9/11 contexts of reception in the U.S., as well as investigate how religious meaning is constructed and maintained by this population. It's goals are twofold: first, to give voice to an underrepresented group; and second, to identify specific hypothesis and fertile grounds for future research. Being wary of the potential for unwarranted assumptions to become embedded within the research design and questions, semi-structured in-depth interviews were chosen as the primary research method because they would allow for both an exploration of the complex intersection under review, as well as an opportunity for the researcher and interview participants to interact more openly and freely with one another around the topic or question at hand.

In this way, this research sought to confront interview participants with questions that reflected the tensions of their lived experience while also giving them space to assert their own perspective and beliefs in response. This research method also allowed for an evolution of the interviews through an iterative process that 
constantly sought and incorporated feedback from participants into future interviews. In addition to exploring their experiences and reactions to post-9/11 contexts of reception, this study also aims to establish a larger exploration of the political claims about Islam within contemporary public discourses in the U.S. It therefore seeks to explore what Islam actually 'is' among this population at an empirical level, and by extension, who exactly Muslim immigrants in the U.S. 'are'.

\section{Access \& Recruitment}

The research population for this study was defined to include adults born in the U.S. between the ages of 18 and 35 who have at least one parent who is an immigrant from a Muslim-majority country. This age range allowed for a comparative analysis between those who remember the September 11 attacks vividly in early adulthood and those who barely remember the event at all from early childhood, being in some cases only 3 or 4 at the time of occurrence in 2001. More than this, the age group represents the millennial generational cohort. In addition to exploring differences between those who were comparatively younger or older in 2001 , a distinct and well-documented generational perspective importantly emerges as a relevant and potentially useful factor for analysis in this regard. Confining the sample to a single generational cohort also allows for relevant generational comparisons between native and non-immigrant millennials in the U.S. In other words, even though there is no clear successive numerical designation of natives the way there is with immigrants, the 'millenial' may 
serve as a de facto category of analysis between second generation immigrants and the children of the native-born. Finally, the requirement that at least one parent be a firstgeneration Muslim immigrant served to keep the criteria for inclusion open to Secondgeneration immigrants of mixed ancestry while explicitly avoiding converts - an issue which would likely raise entirely different questions that are neither anticipated by the research design nor explicitly sought by the research questions.

Interview participants were recruited using convenience sampling. Organizations that identified as 'Islamic' as well as those from Muslim-majority ethnicities and nationalities were solicited by the researcher for access to their membership populations for the purposes of recruitment. Those organizations whose mission was explicitly religious did not grant access to their membership populations. Those organizations whose mission was explicitly educational, or associative in the public sphere, frequently granted access to their membership populations for recruitment, passed on notice of the research opportunity to others who wanted to 'discuss their experiences in post-9/11 America', and had even offered their administrators for participation in the research. Public events with titles such as 'voices against Islamophobia' and 'Muslim voices against extremism' also served as fertile venues to discuss the research study with potential participants, which included members of public, educational, and religious organizations. 
The primary challenges to access and recruitment of research participants, for organizations and individuals alike, took three primary forms - each of which presented significant challenges to the recruitment process, not all of which were expected. First, the strain of public inquiry surrounding current events resulted in a heavy barrage of requests for meetings and interviews with a range of entities, public and private, educational and religious, political and apolitical. Every organization I encountered described being inundated by this wave of outreach and inquiry following terror attacks resulting in long queues of interview and meeting requests that they simply could not, and often did not want, to keep up with.

During the recruitment period from January to April of 2016, two tragic events allowed this dynamic persist while I attempted to recruit research participants. The first were the Paris attacks coordinated throughout the city to target civilians in midNovember of 2015. January and February of 2016 were spent dealing with the social and political fallout from this event for many student and community organizations as well as mosques. By mid-March, when it had finally become easier to make contact organizations and discuss my research my efforts were beginning to bear more fruit when the second major event, the Brussels airport bombings, killed or injured more than 300 civilians in Belgium and reignited the tense social and political atmospheres that had made recruitment so difficult in the early months of January and February. 
In response to this environment, all I could do was remain persistent - aiming to elevate the request for interview participation above others on the grounds that it was scholarly research being undertaken at a public university. In many cases this tactic was successful, eventually resulting in enough contacts and subsequent interviews to complete the research effort. Socially tense and politically contentious environments did also, however, create serious problems for conducting exploratory research across the larger geography of the Pacific Northwest as I had planned. Due to additional time constraints and contact/scheduling difficulties, the Seattle Metropolitan Area, initially included in the geographical sphere of this research along with a goal of 20 interviews, was excluded, leaving 10 interviews to be conducted throughout the Portland Metropolitan Area. Even this was difficult to achieve given the national political climate and the measures Islamic organizations and local communities were taking to address matters and remain proactive on their own.

Second, suspicion of the intentions or motivations underlying the research largely due to its subject matter focus on Muslims, was a significant but less daunting challenge. When encountered, especially at Mosques but also among some individuals at public events, the nature and purpose of the research needed to be openly and candidly discussed in a manner that sought to address these issues. While my willingness to do so was enough to address the concerns of some, it was not enough for others. Given the social and political environment described above, this often became a connected secondary concern that further vexed my initial efforts. 
The third challenge had to do with potential familial and communal repercussions related to research participation. While the research ostensibly sought to explore the experiences of second-generation Muslim immigrants in a post-9/11 America ("if you don't speak up for your experience, someone else will" was a frequent appeal I made) it inevitably dealt with interstitial interactions between faith, family and the larger community that bound them together. This factor alone, in my opinion, explains the majority of the resistance I encountered at Mosques and other explicitly religious organizational gatherings. If someone's daughter or son were to participate and be identified in the research material contributing to harmful stereotypes or worse, they inadvertently help forward a research agenda perceived in some way to work against Muslims in the U.S., such exposure would constitute a liability for the family and the local communities to which they may be tied. As such, when weighed against possible familial and communal repercussions, the opportunity for research in these contexts may constitute an unwarranted risk for individuals and communities who feel as though they are weathering a larger social and political 'storm'.

To address these challenges, I relied to a large extent on my Iranian background, knowledge of Islamic cultures and norms, and existing personal relationships with the larger Muslim-American community to gain entrée. My mother was born in Iran and in the late 1970 's, with some twelve members of her family, emigrated to Salem, Oregon. I spent my first birthday in 1982 in Iran, in the towns of Karraj and Arak, during the IranIraq war. I returned again in 1985 and 1990, spending a total of nearly one year being 
raised there, often returning with a thick accent - more proficient in Farsi than English. I believed this helped get interviews with Iranians, and to this end also think that it would have been even better if I spoke Arabic as well.

For some of the groups I approached for participants, the fatigue of constant inquiries and interview requests meant that they no longer had the capacity (nor at times even the inclination) to begin evaluating each request's respective merits. And while my general persistence and continual reminders that I was engaged in university research were effective in raising my profile to a large degree, I also relied on introducing myself as 'Shahriyar' to establish a very real familiarity, an 'insider status' that would encourage responses under the auspices of customary and normative familiarity and respect. Combined with my resources on Portland State University campus, and the helpful advice and cooperation of faculty and engaged community members and student leaders, I was able to eventually gain access to a range of groups both on and off campus and successfully recruit after considerable effort and delay, in person using convenience sampling, a total of 10 research participants.

Three participants were recruited at public events - both on Portland State University campus, but which included a majority of non-students in the form of interested community members and issue-organization representatives. Three other participants were recruited from Islamic student groups at the university. The final four were recruited from national and ethnic organizations that had met at the university in 
the past, but predominantly gathered at venues throughout the larger Portland Metropolitan area - of the five Iranians included in the research sample, four were recruited in this way. This also reflects the extent to which I had to rely on personal entre within the Iranian-American community in Portland and my knowledge and use of Farsi to gain access to potential interview participants.

Five Iranians, two Palestinians, a Jordanian, a Yemeni and a Bosnian provided both a healthy diversity from within the Muslim world, as well as a more accurate proportional representation of Muslim immigrants in the U.S., with Persians and Arabs being much closer in their respective populations counts than outside the U.S., according to the 2010 U.S. census and other organizational estimates. Country of origin was seen as potentially important factor for two reasons: first, Alba's (2005) work on second generation immigrants in Europe and the U.S. highlights the 'path dependence' of different groups. Ignoring the historical and cultural diversity represented by each Muslim immigrant group's country of origin would be potentially reductive in assuming a uniformity in the respective impacts of their different histories and cultures in relation to the research questions. Second, different countries of origin conform to different sectarian divisions within Islam. Iranians, for example, are overwhelmingly Shia while most Arab nations are Sunni. Within each Sunni-majority nation, moreover, different political histories and minority groups structure attitudes and practices in different ways - with the Druze in Lebanon and Syria and the Copts in Egypt being prime examples. Lastly, four women and six men represented a sample tilted more toward men, but 
given my initial concerns for female participation, among both Persian and Arab immigrants, this was something I decided to work with and account for given my small sample size, and exploratory nature of pilot research in general.

Research Sample

\begin{tabular}{|c|c|c|c|c|c|c|}
\hline & Gender & Age & Occupation & Education & Married & Country of Origin \\
\hline Mahdi & Male & 35 & Unemployed & Bachelors & No & Iran \\
\hline Hassan & Male & 32 & Student & High School & No & Iran \\
\hline Jafar & Male & 21 & Student & High School & No & Palestine \\
\hline Farah & Female & 19 & Student & High School & No & Yemen \\
\hline Sholeh & Female & 27 & Auditor & Bachelors & No & Jordan \\
\hline Ali & Male & 35 & Entrepreneur & Associates & Yes & Iran \\
\hline Maryam & Female & 34 & Pharmacist & Doctorate & Yes & Iran \\
\hline Shahin & Male & 34 & Business Analyst & Masters & No & Bosnia \\
\hline Nemah & Male & 24 & Bank Teller & Bachelors & No & Iran \\
\hline Marjan & Female & 27 & Student & Bachelors & No & Palestine \\
\hline
\end{tabular}

Table 1.

\section{Portland, Oregon as a Strategic Research Site}

Prior research on New York and Los Angeles has highlighted the comparatively favorable effect particular geographies can create for second generation immigrants (Kasinitz, Mollenkopf \& Waters, 2004; Kasinitz et. al., 2008). While these authors have focused on the legacies of prior waves of immigration in shaping these unique 
environments for the children of immigrants, Alba \& Nee (2003) have highlighted several elements that may help to explain the comparative favorability of some contexts of reception in these cities that vary from other national, regional and local contexts. In their formulation of New Assimilation Theory, they identify 1) the valorization of inclusion among mainstream institutions, 2) a resultant belief that public institutions will protect immigrants from social and economic discrimination in the public sphere - and especially in the work place, and 3) the reasonable predictability of parity of life chances with their peers in the mainstream. "The valorization of inclusion has been sufficient to produce public and private policies intended to foster it within the framework of equality under the law [...] diversity as a social value has gained support in many sectors of the American mainstream" (Alba \& Nee, 2003:280). New Assimilation Theory, therefore, "highlights the role of the state by implicating it directly in the institutional mechanisms that ensure reasonably predictable chances of success for the second and third generations [of immigrants]" (281).

Portland has been the identified by numerous research studies as a site of the 'new urbanism' (Jarvis \& Bonnett, 2013; Trudeau \& Kaplan, 2016; Song \& Knaap, 2003; Lund, 2003; Cabrera et. al, 2016), which focuses on the reduction of urban sprawl, the integration of work and residence, the city and natural environment, and the construction of open spaces that promote integration of new residents into established communities and discourage residential segregation. Portland also has a reputation of being a politically progressive city consonant with the 'valorization of inclusion' that 
Alba \& Nee (2003) describe, as well as a history of working to engage local communities through local governments in developing the new urbanism referenced above. As such, it is seen as a unique environment that has not escaped ubiquity of post-9/11 contexts of reception and their transformative effects at the national level, but nevertheless managed to mitigate its more extreme effects in maintaining a comparatively favorable context of reception in the manner of its 'new urbanism'.

The importance of this unique environment for exploratory research lies in its distinctiveness. First, research participants may be more likely to explicitly reference and interact with such an environment in their answers to interview questions - i.e. Portland makes often much ado about itself, so they may make much ado about it as well or have an opinion where they otherwise would not. This awareness of place, and of the public intentionality with which the state is implicated in the institutional mechanisms that drive the function and development of the city, is of significant utility in the exploration of how individuals perceive public attitudes in a variety of contexts, how they relate themselves to the mainstream, and how confidently they can estimate a reasonable predictability of life chances relative to the mainstream. Second, the distinctiveness of Portland may allow for the triangulation of research results, specifically as they may pertain to other geographies. For example, a potential result $(x)$, given what we know about Portland relative to another city $(y)$, gives rise to the following question (z). In this manner, pilot research is here conducted with the 
relatability of its distinctive geographical setting in mind for the purposes and implications of future research.

\section{Interview Protocol}

The interview protocol (Appendix A) was comprised of five sections. The first, on Islam, sought to explore and probe the construction and maintenance of religious meaning in the context of political identity (Mamdani, 2002). Particular emphasis was placed on identifying the form of historical consciousness operating at the heart of how they understood Islam. Participants were asked to define Islam 'in their own words' and if they saw more similarities or differences between themselves and other Muslims on the question. They were asked three further questions designed to explore the fault lines between Localized Islam and Globalized Islam. These focused on the role of takfir, the pronouncement of other Muslims as 'non-Muslims', the historical role of national, ethnic and familial identity in shaping Islam, and lastly the role of local traditions and cultures - whether they 'add to or subtract from it'. In this way, the research protocol sought to enable a comparative focus of the way participants actualized their historical consciousness in describing their respective opinions on nationality, ethnicity, family, and local traditions and cultures. This section also gave research participants the opportunity to more openly speak to the broader definition of Islam, in both abstract and practical terms in the context of their lives as Second-generation Muslim immigrants in the U.S. 
The second section of the research protocol focuses explicitly on the U.S. mainstream and sought to gauge experiences and reactions to post-9/11 contexts of reception, as well as their conception of self in relation to the broader society. The first two questions explored whether living in the U.S. 'helped or hindered' their practice of Islam and whether they saw U.S. society as 'more friendly or more hostile towards Muslims and Islam'. In addition to intersecting with the questions on Islam, these questions aimed to measure their experiences of post-9/11 contexts of reception through the lens of political identity. The following two questions directly focused on their predictability of life chances, where they are asked to define success and then assess their ability to achieve it, and their place as either 'inside or outside' of the U.S. mainstream. Finally, they were asked about any tension points they observed between their lives as Muslims and as Americans, and whether they lived 'in two worlds or one, or both'. These last sets of questions were designed to directly explore Alba \& Nee's (2003) criteria for assimilation into the mainstream as well as the boundary processes outlined by Alba (2005) and by Portes and Rumbaut (2001).

The third and fourth sections explore two factors relevant to both constructions of Islam and the U.S. mainstream: family relationships and peer networks. Specifically, Foner's (1997) account of family as an 'inner world' where a dynamic interplay exists between culture, structure, and agency, as well as Portes \& Rumbaut's (2006) role of religion as a source of 'refuge, respect, and resources' guided the this section to explore the role of religion in family relationships and the presence or absence of conflict 
related to processes of selective acculturation. The section on peer networks sought to gauge their level of social activity and the primary means of interaction, whether it was predominantly person-to-person, long distance contact or social media-based. Finally, the last section had basic demographic questions on age, occupation, education, marital status, and family country of origin.

\section{Conducting the Interviews}

A total of 10 interviews were conducted from January 2010 to April 2010 throughout the Portland Metropolitan Area. Interview sites consisted of restaurants, coffee shops, and open places such as public plazas and parks. Interviews lasted an average of 30 minutes and were electronically recorded using a mobile recording device. This figure reflects considerable divergences between interviews, with the longest lasting 40 minutes - more consistent with the length of interviews found in exploratory research. Others, however, lasted between 15 and 20 minutes, with the shortest at 7 minutes. The shortest interview, for example, consisted of short one-word answers, or strong opinionated statements with long pauses and silences in between. Prompts to continue were met with silence, and some questions were passed on altogether. Some of the intermediate-length interviews saw participants elaborate at length in some sections, only to provide short responses in others.

Finally, as the interviews progressed overall times did increase as I became more adept at approaching questions in a manner that anticipated and avoided the lapses and 
tensions that brought discussions to a quicker end in prior interviews. Even though interviews were comparatively shorter than I would have liked, it is important to note that research participants were confronted with a complex array of interlocking questions on topics of considerable public, private, and familial tension. For their part the research participants, even when curt, were to the point and managed to provide a relatively rich base of data from which to draw for the purposes of exploratory research.

They were then transcribed on an ongoing basis as interviews were completed and stored on an encrypted password-protected hard drive. Interview participants were required to view and voluntarily sign an informed consent form (Appendix $B$ ) in order to participate in this research study and before the interview could begin. Each interview participant was also given added verbal assurance of strict anonymity and the use of pseudonyms during transcription and coding.

The interviews appear to have gone quite well, with no incident or adverse reactions from research participants. There were several moments when respondents paused to think about a question or 'get comfortable', particularly on the section on Islam. As the interviews continued on into subsequent sections, participants who had given short answers or skipped questions in the section on Islam would return to earlier questions and link them with other responses, or speak in greater depth to answers they had given earlier. Several interview participants described the interviews as 'fun' and 'exciting', explaining that they realized they enjoyed being able to speak to an 
intersection they rarely were given the opportunity discuss and themselves rarely thought about.

\section{Data Analysis}

Research interviews were conducted and transcribed in three waves. Emergent themes were identified in each and used to adjust the next interview protocol accordingly. Taken together, the identified emergent themes guided not only the cumulative progression of the research process, but also the comparative analysis of interviews in individual relation to one another within the research protocol. Rather than a random or ad hoc selection of questions for comparison across interviews, using the emergent themes to identify questions for comparison between the interviews allowed for a linearity of analysis between the research as it was unfolding and the research in its final form. What emerged had been progressively explored in greater depth by focusing on specific questions in successive iterations of the interview process. These questions were later identified as the basis for comparisons between interviews, thus allowing for nuanced contextual understanding at a relatively high level of thematic abstraction.

While the earlier interviews did not benefit from the insights of themes that emerged from them, they remain an important part of a cumulative record upon which the rest are based. Thus, the content of earlier interviews remains of sufficient substance and quality such that, while later interviews benefited from new insights and 
observations, they remain equal in qualitative terms with every other interview as mutually-constitutive elements of a continuous body of research data.

The first set of emergent themes concerned three primary issues. First, that participants expressed sentiments that appeared to conform to both Globalized Islam and Localized Islam, but did not break cleanly between the two. There was an apparent continuum between the two that I explored in greater detail during the later interviews. Second, the research participants recognized the existence of Islamophobia and discrimination, but also held to a reasonable belief in the protections afforded to them by mainstream institutions in the public sphere, as well as in their future life chances relative to other groups. In other words, while they acknowledged Islamophobia, they did not think that it would affect their integration into U.S. society. Third, there were apparent tensions between family life and U.S. society. Research participants frequently centered on negotiating between these two worlds such that they avoided conflict, never 'coming to a head' so to speak.

The second set of emergent themes focused almost exclusively on the impact of gender. The first research participant in this second group, Farah, even gave feedback on the order of the sections after her interview - suggesting that the order between the first section, which was on Islam, and second section, which was on U.S. Society, be switched in order to ease into a discussion of Islam after U.S. society. I took this advice and found it to be useful in getting more out of participants on the section on Islam 
without losing anything on the U.S. society. The first emergent theme concerned the link between women and localized Islam. In addition to being more strident in defending the role of local customs and traditions within Islam, they also began to emerge as 'cultural lynchpins', or as I began to see them: as 'performers and reproducers of culture' around which family groups and ethnic identity were centered. Hence, the second emergent theme focused on the role of women in constructing religion as a 'glue' binding family together and representing national and ethnic realities which remain meaningful for immigrant groups in the U.S. Finally, women spoke of living 'between two worlds', while men had either expressed feeling like they lived in 'one world' or 'within one or the other'.

The relative complexity of these observations over time, viewed across the twenty questions present in the research protocol, gradually narrowed the analytical focus down to several key questions, specifically questions 1 and 3 on Islam, questions 6, 8, 9 and 11 on U.S. Society, and questions 12,13 and 14 on family (Appendix A). These themes allowed for a relatively straightforward comparison of interview transcripts. Thus, no data analysis program was used because of the continuities present in the application and development of the research protocol and data analysis itself. Added to this the relatively small number of interviews, it was determined that what was ultimately a manageable task requiring only ink and paper to conduct manual scissor-sorting, to use an antiquated methodological term, could be complicated by 
adding an unnecessary middle step that costly in terms of both time and effort and gaining little in return.

\section{Limitations}

The limitations of this research extend primarily to issues of generalizability, and also to the nature of the sampling method. The research focused on Portland as a strategic research site, and while there may also be other such sites with similar qualifications, there are a greater number of divergent than convergent geographies in this sense. Thus the results of this research are tied to the distinct geography in which it was conducted. Furthermore, with a sample size of 10 interviews no meaningful statistical generalization is possible. This research can only be regarded in future research as a source of primarily theoretical and only limited empirical contributions.

The representativeness of the sample, while closer to the description of the 'average Muslim man in the U.S.' offered by Portes \& Rumbaut (2006) nevertheless reflects assumptions about the first generation of Muslim immigrants. In order to construct a truly representative sample for the second generation, such a composition must be balanced against reliable data that paints a more accurate picture of this population within the larger research literature. Lastly, convenience sampling was a way to 'break in' to an area of study for the purposes of pilot research. It does not represent a reliable sampling method for future research. Alternative sampling methods should be considered accordingly in future research. 


\section{Chapter 5}

\section{Analysis \& Findings}

The results of this study are here organized into two sections. The first presents findings on Research Question \#1 and identifies two important factors that I believe should be the focus of future research: public institutions and gender. It further offers a hypothetical model for understanding the differential effects various actors within public and private domains can have as sources of discrimination. The section concludes with a discussion of how research participants have responded to the emergence of bright boundaries within post-9/11 contexts of reception by engaging in 'boundary shifting'.

The second section presents findings on Research Question \#2, identifying family and the context of reception as two sites where the construction and maintenance of religious meaning are seen to occur. The unique complexities of selective acculturation processes are identified as a useful analytical concept for future research on constructions of Islam with respect to second generation Muslim immigrants. It concludes by outlining a hypothetical typology of different constructions of Islam among research participants, and presents a vignette of each type as potential grounds for future research. 


\section{Section 1:}

Research Question \#1: How have Second-generation Muslim immigrants experienced and reacted to post-9/11 contexts of reception?

While the World Trade Center attacks on September 11, 2001 may have fundamentally altered the context of reception for Muslim immigrants in the United States, second generation Muslim immigrants are continuing to assimilate as previous generations of Muslim immigrants have done before them (Gest, 2012; Wike \& Grim, 2010). While the paths they navigate today are certainly more complex, politicized, and often fraught with controversy, second-generation Muslim immigrants who participated in this study continue to resemble the image of their parental generation: as an upwardly mobile group focused on economic achievement and educational attainment, who exhibit confidence in the protections afforded to them by public institutions as well as a positive view of their life chances relative to other groups in the U.S. This resembled linear and not reactive ethnicity according to Portes \& Rumbaut's (2006) analysis or religion outlined in my theoretical framework. The research findings speak to each part of the research question concerning both experiences and reactions to post-9/11 contexts of reception.

Presented first is an in-depth account of experiences of discrimination. At critical issue appears to be the role played by public institutions and gender. With respect to their reactions, interview participants exhibited a strong confidence in the protections 
afforded to them by state institutions in the public sphere. Building on this, secondgeneration Muslim immigrants appear to further react to post-9/11 contexts of reception by redrawing bright boundaries, moving them to include themselves within the American mainstream as genuine members who are similarly alarmed by Islamic terrorism and mutually invested with fellow citizens in the fight against violence and extremism.

Finding \#1: Experiences of Discrimination in the U.S. - The Role of Public Institutions and Gender

Research participants clearly and candidly recounted their experiences of discrimination. They indicated an awareness of discrimination toward Muslims in the U.S. as well as an awareness of the historical legacy of discrimination in the U.S. more generally. Shahin, for example, observes that "racism in this country is still a prevalent issue. Basing somebody's skin color, or name even, if it sounds Muslim, there's already a judgment cast upon a person. So do I believe it exists? Yes. Do I believe it is hindering somebody to be successful? No." In exploring this apparent resilience during the interviews, two primary dichotomies emerged and appeared to function as evaluative criteria in specific contexts: 'ignorance versus culpability', and 'individuals versus institutions'. What emerges from my subsequent analysis of these two dichotomies is a framework that roughly indicates the relative consequentiality of some events and the relative inconsequentiality of others. 
In post-9/11 contexts of reception, for example, discrimination is experienced within a variety of contexts and from a variety of directions. Individuals and institutions acting across public and private spheres can have dramatically different impacts as different sources of discrimination. Private individuals, for example, are seen as the most inconsequential - easily and often dismissed as 'ignorant' by research participants who feel supported and protected by state institutions. Public institutions, , usually represented by the state however, have a lasting and transformative effect as sources of discrimination for second generation Muslim immigrants, reinforcing the significance of the state as an actor in what Alba \& Nee (2003) have described as processes of 'new assimilation'.

The 'Ignorance Versus Culpability' Dichotomy

The 'ignorance versus culpability' dichotomy appeared in relation to authority, or an authority figure. For example, participants recognized that various individuals may hold ignorant views and remain susceptible to Islamophobia for that reason. The case could be that, according to several research participants, an individual has not had the exposure or requisite experiences to challenge their existing views. The 'door remains open' for them to learn and grow, so to speak.

Authority figures - those sanctioned with institutional power by virtue of a position they occupy or a status they hold (such as teachers, public officials, state agency administrators, police officers etc...), however, exist according to a different 
evaluative criterion. They should know better, by virtue of their position - whether it is because they have a responsibility to exercise power on behalf of the public good or because they represent a particular public institution. Their ignorance is not an excuse, the reasoning goes. They are viewed as culpable by virtue of the structural position or role they occupy. This difference was manifested quite demonstrably during the interviews - defining the significance of some events and the insignificance of others.

The most compelling example of the 'ignorance versus culpability' dichotomy came from Farah. She relays two stories. The first involves a classmate asking her at school: "how do you feel now that your leader died?", referring to the killing of Osama Bin Laden by U.S. Special Forces in 2011. Her response illustrated a view of the classmate as an individual: "so if I'm Muslim and he says he's [Bin Laden] Muslim, then that means we're absolutely the same, think the same. They think that I justified his actions just by being Muslim... They just don't know any better, so I couldn't blame them in a way." She did not indicate the event to have shaken her or colored her experience of school or non-Muslims in any adverse way.

Her second story involves a similar situation in high school, where she was allowed to take a test she had missed due to illness. In the detention room where she was scheduled to take the exam because there would be a staff member present who could administer it, her backpack began beeping - an alarm she had forgotten about had gone off in her backpack. 
“Two guys started saying 'is that a bomb?' ... I was just like 'that's just my alarm, you guys are just being stupid'. And I didn't care about that, cause they're just idiot guys. Again it just goes back to how I thought about it [as ignorance]. But then the teacher that was there, she was like, 'oh I'm really glad, I thought you were going to explode on us.' That's what she said to me. Yeah, and this is an adult, somebody who I really thought would stand up to the bullying I was getting and say something against it... I was absolutely speechless. I didn't even say anything. I just sat down..."

The event shook her because the teacher was not simply another ignorant person she could forgive; she was an authority figure - a part of the broader institutional structure she relied upon for the basic sense of safety and security required to forgive the ignorance of others, instead of being affected by it. Similar examples put forward by research participants included irresponsible portrayals of Muslims in the U.S. media as well as ignorant and inflammatory speech by major candidates for national political office. In each case the event is more significant than, and goes importantly beyond, the relative inconsequentiality of individual ignorance. Perceptions of ignorance in the context of legitimate power and sanctioned authority structures, according to this study, do not appear to be at all inconsequential for the children of Muslim immigrants. Rather, they appeared to affect research participants on a deeper level. 
While this research is strictly exploratory, it can offer a tentative hypothesis as to why this is: authority figures ostensibly represent the state. Their actions, therefore, can hypothetically be seen to reflect upon state institutions and the character of the host nation in general. This could be disruptive on a deeper level for a number of reasons, the most apparent of which appears to be the role played by immigrants' confidence in civil rights protection afforded to them by state institutions. Through experiences of discrimination with authority figures they associate with the state, and therefore the host nation, the confidence upon which a belief in future social and economic opportunities rests may become underimined.

\section{The 'Individuals Versus Institutions' Dichotomy}

The 'individuals versus institutions' dichotomy emerged in relation to experiences of discrimination in Mosques and among other Muslims, but can also be applied to a variety of other non-Muslim contexts. Here the actions of an individual stand in stark contrast to the actions of an institution, both in moral and civil terms. Of the two research participants who described themselves as practicing Shia Muslims, both recounted adverse experiences praying among other Sunni Muslims. The first, Ali, recounted the following: "I've prayed at Portland Community College where another Muslim came and, you know I'm a Shia, a Sunni person came next to me, sat next to me right after my prayer and told me 'brother I just wanted to let you know that you prayed wrong' and I was like 'I didn't know there was a wrong way to pray' you know?" Here, 
Ali responded to the opinion of another individual with his own, and wove the incident into his explanation of how he thought about Islam as "giving the same messages, it's just in a different language."

Hassan, by contrast, recounted the following: "I was, uh, not allowed to pray in a Mosque... And not just because it was that Mosque's fault, it's just because what was traditionally taught to one of those brothers at the Mosque was thinking that my prayer would have ruined his prayer." Here we see that what was 'traditionally taught' to a single person was enough to prohibit Hassan's prayers from the Mosque as a whole. Consequently, Hassan observes that "culture does subtract usually from the purity of religion..." Of critical importance appears to be the role of institutions as actors in processes of inclusion and exclusion - between both Muslims and non-Muslims in the public sphere. The assignment of culpability, moreover, appears to occur strictly in relation to the public sphere.

Thus, the role of individuals and institutions within public and private spheres can be hypothesized to determine the relative impact and perceived consequentiality of discrimination for research participants, with public institutions being the most harmful and private citizens the least. The impacts of perceived discrimination from political candidates and community organizations appear to exist in the middle of a larger continuum defined by these poles. In the 2016 U.S. Presidential campaign, for example, we have seen the Republican nominee for president discuss a possible moratorium on 
immigration from Muslim-majority nations, as well as organizational support for such measures from immigration reform groups and 'watchdog' organizations. While they are seeking public office and operating openly in the public sphere, respectively, political candidates and community organizations do not yet occupy state institutions and remain open to criticism in the context of democratic elections. Coalitions can be built against them and solidarities formed. Once occupying position of authority within state institutions, however, this analysis suggests the consequentiality of their actions may be of a singular magnitude, indicated in the following table.

Relative Effects of Discrimination:

\begin{tabular}{|l|l|l|}
\hline & Individuals & Institutions \\
\hline Public Sphere & Political Candidates & The State \\
\hline Private Sphere & Private Citizens & Community Organizations \\
\hline
\end{tabular}

Table 2.

The Indirect Effect of Gender: Family Structure and Religious Visibility

Family structure and the public visibility of religious dress emerged as factors that consistently determined significant differences between research participants. 
Both are fundamentally related to gender. Thus, gender is seen to be manifested as an factor of influence indirectly through them.

Marjan wore a headscarf to her interview and indicated she wears it regularly. "Since I'm covered, and walking around at night, I'm definitely more aware. I feel like I have to be on watch all the time if I'm alone... People tell me to go back to my country all the time, and tell me that I can take my scarf off." This observance is connected with her family structure, which is all-Muslim. "I grew up in a very strict household, so religion and culture came before anything else. Family always comes first, so I still definitely hold onto a lot of that. It's definitely affected me into adulthood, following the religion and the way we do things."

Ali, by contrast, is not visible the way Marjan is - subject to the requirements of a religious dress code. He is able to otherwise 'blend in' in this regard. His family structure is also not all-Muslim. "My wife is American and my wife's family are very conservative Catholics and hardcore Republicans. So I totally see the other side and we have our own conflicts on drinking alcohol, eating pork, who we're gonna vote for, and um... but again at the end of the day they're great human beings. And, you know, they had me cornered as a Muslim for the longest time. Finally, they've got to know me so I think I've broken that barrier too."

Because bright boundaries rely on the successful identification of an individual as a Muslim, the consequences of religious dress can be seen to apply 
differently between men and women. While there are both male and female forms of Islamic religious dress, the normative requirement of religious dress is more often seen as compulsory, and applies disproportionately to women in the context of contemporary immigration to the U.S. In this way, the relative visibility of Muslim women effectively determines their relative vulnerability to the vicissitudes of bright boundaries, compared to Muslim men.

The experiences of Marjan and Ali show them to be respectively more and less vulnerable in the public sphere in real terms - as visible subjects to be noticed in, and accordingly subjected to, Islamophobic post-9/11 contexts of reception. Because Islamic dress is often a matter of familial influence among Muslim immigrants in the U.S., familial composition (i.e. how mixed or culturally-diverse) can be seen to structure and determine the extent and nature of contact with non-Muslims in the public sphere. This affects, in turn, their relative visibility as well as the way in which they interpret their interactions with others. And while family structure and religious dress are certainly interrelated as distinct factors, they both fundamentally hinge upon and reflect the larger influence of gender.

This appears to reflect the fundamental insights of recent research on the use of the hijab by second generation Muslim immigrant women in the U.S. to construct both individual identites and autonomous spaces within the public sphere (Ali, 2005; Williams \& Vashti, 2007). It also speaks to the manner in which the visibility of religious dress can 
impact the nature of what Dubois' referred to as 'double consciousness' among members of a cultural minority and which Anzaldua (1987) has extended to include the experience of immigrant women. In this way, the use of the hijab and other forms of visible religious dress, far from being the figurative 'shackles' for Muslim women imagined by native non-Muslim interlocutors in the West, represent an expressive "patois, a forked tongue, a variation of two languages" that communicates for Muslim immigrant women "realities and values true to themselves" (Alzaldua, 1987:35). Anzaldua (1987) has observed the conspicuousness of these linguistic and expressive variations, as well as the historical challenges and consequences faced by the immigrant women who bear them.

The Direct Effect of Gender: Identifying with the Mainstream

Nearly every research participant, all but two (who still expressed positive views of their life chances), responded affirmatively to the following question: "Looking at yourself, how do you personally see yourself within American society? Do you see yourself as 'inside' or 'outside' of it? Are you a 'member'? How do you believe American society sees you personally?" (Question 9, Appendix A)

Research participants were all quick, and to the point:

"I see myself as inside" - Sholeh.

"I do see myself as an American" - Farah. 
"I believe I see myself as a member" - Marjan.

"I feel like I'm a member and I'm a part of them" Maryam.

"I see myself as a member..." Shahin.

"I consider myself a member of the United States" Nemah.

"I see myself as 'in'. I’m an Oregonian” Ali.

"I do include myself in the society, I do think I am an American" Jafar.

Here we see a clear and unequivocal view emerge among research participants of themselves as 'inside' U.S. society. They appear to meaningfully identify as members, even within post-9/11 contexts of reception defined by Islamophobia - which they also clearly recognize. They see themselves as 'in', but the manner in which they do so differs sharply according to gender.

Two worlds, One World, \& In-Between

While most respondents viewed themselves as members, identifying 'inside' the U.S. mainstream, male participants who elaborated on their answer above indicated a feeling of 'inclusion amidst difference'. They described themselves as not only living in 'one world' but also as actively and constantly engaged in the task of breaking down barriers 'between worlds'. "If I walk into a room and somebody looks at me with my beard, immediately they might think, 'oh this Muslim guy I don't know where he's from'. 
But the moment I communicate with them their whole idea of who I was when I walked in the door changes. So I consider myself 'in'”' (Ali).

Similarly, Shahin expresses a view where he is crossing the distance between himself and others: "when I speak with, you know, with other Americans... it's kind of funny because they can sense my accent... and so that's always a topic of curiosity. And so that's, I think, they will always know I'm not from here, but I do think they accept me as being a part of this country." His inclusion appears to be supraordinate here. That is, it appears to be regarded categorically above, or prior to, any other confounding or complicating factors such as Islamophobia or even subtle recognitions of his foreign accent. For research participants, their sense of membership of was often expressed in interviews as a given, something they simply assumed before encountering or considering the realities of the social field itself.

Female research participants, however, were split according to whether they wore a headscarf or not. The two (of four) who did, Farah and Marjan, gave responses that were somewhat conflicted compared to their fellow research participants - both male and female. Farah, for example, put her role as an 'active member' of her family at issue: "I think that part of American society is that to be a true member of it, is that you really have to have a tolerance for all kinds of people and all types of mentalities. But if you're such, if you're so into a specific group... then it's hard to accept those people as people but more as outsiders. So I do see myself as part of American society, but more 
internally than what I externally portray." In other words, because she actively performs and reproduces Yemeni culture within her own family, it is natural for Farah to see others who perform similar roles in different groups as outsiders. In this way, perceptions of ethnic 'otherness' between immigrant groups can be manifested among immigrants themselves in the U.S. It is also important to note that she says she sees herself as part of American society 'more internally than externally'. This indicates her performance and reproduction of Yemeni culture and family norms could be more predominantly externalized, and performative, while her sense of membership in the mainstream is comparatively internalized, and not necessarily performed or reproduce in the same terms.

These observations connect importantly with another significant finding of this study: when asked: "Do you live 'in two worlds' or one, or more than two?" (Question 11, Appendix A), every female research participant responded that they lived 'in two worlds' or 'more than two' while every male research participant asked responded that they lived in 'one world'. Where male respondents spoke of breaking down divisions and barriers within 'one world', female respondents gave the following responses:

"I would say two. I mean, I think most Arabs would describe it as two... I know American culture doesn't really regard elders and previous generations with high regards, but I mean, with Arabs and with Muslims its everything" - Sholeh. 
“Probably more than two... one world when I'm with my family and when I go to the Mosque, and close family friends. And then a different one when I'm at work or school" - Marjan.

"I live in seventeen... It's hard... you feel yourself just kind of bled in the middle where you don't' know which way is better. You know what I mean? So I find myself in my own world, really. Like there's thing I will never tolerate from my family and there's thing I will absolutely never tolerate from my American friends" - Farah.

One can exist at any given time within one world or the other, as with Sholeh and Marjan. But one can also exist between worlds, as evidenced by Farah's account of her 'own world' amid the 'seventeen' she navigates as an active member of her family, as well as the broader society she lives and meaningfully participates in. Here, gender can be identified as a significant factor influencing how research participants experience and react to post-9/11 contexts of reception and how they corrected or redraw bright boundaries in response to them. With such a small sample, however, the results of this exploratory research can only suggest gender as a relevant frame of analysis for research on the children of Muslim immigrants, and furthermore, that it may remain a salient division within processes of selective acculturation. Thus, selective acculturation processes are further emphasized as fertile grounds for future research, with an 
additional focus on the indirect effects of gender through family structure and the visibility of religious dress.

Finding \#2: Evidence of Assimilation? Resilience within Post-9/11 Contexts of Reception

Despite the effects of post-9/11 contexts of reception, research participants continued to express a positive view of their life chances and future opportunities in the U.S. When asked: "For you, what does it mean to be successful in America? Do you believe it possible for Muslims to succeed in America? Do they have the same chances for success as everyone else or not? Why?" (Question 8, Appendix A) every respondent indicated an unequivocal belief in the possibility of success as they understood it and, at a minimum, an equality of life chances and opportunities for Muslims in the U.S. Two examples of more simple, clear-cut responses were:

“Yeah, definitely. To be successful in America, it's the land of opportunity. Education and having a family, like, really Muslims can do that same thing." Maryam

“Absolutely, I do feel everybody has the same chance. I don't think religion hinders one from achieving what they want to achieve." - Jafar

Others wrestled more explicitly with issues of discrimination in ultimately reaching the same conclusion: 
"Whereas Muslims, I feel like they do have the right and the ability to be successful in America. Obviously... people are looking at Muslims in a different way, and that shouldn't be the case. But they're in America, they have to take advantage of what they have and do things that is right, and not be looked down upon because of their actions, just because of stereotypes...

Researcher: "So you don't see stereotypes as a barrier that affect life chances?"

"No, it should not. Definitely should not. In America you have the opportunity to do whatever you want to do and you should definitely take advantage of it." Nemah

Another respondent expressed the sentiment in a similar manner.

"If my goal, for example, is to be CEO of a company and I'm starting from the bottom, of course it's going to be difficult... because for one thing I'm female, I'm a minority, I'm Muslim, so I got the three threats know what I mean? So of course it's gonna be a hindrance.

Researcher: "Is it possible?"

"It is possible, but it's not gonna be easy... Of course it's possible. If you really put your mind to it, you're gonna work your ass off until you get there." - Farah 
Research participants clearly recognize the prevalence of stereotypes and the many possible intersections between post-9/11 contexts of reception and more traditional forms of discrimination rooted in the historical legacy and contemporary reality of U.S. society. At the same time, their perception of available opportunities and life chances does not appear to be determined by them. For whatever reason, in the presence or absence of discrimination, second-generation Muslim immigrants in this study consistently and reliably held to the idea that life was 'up to them' - that they would determine the future as architects of their own destiny.

Taken together, the positive view of one's life chance and the perception of support amid discrimination appear to result in an impression among research participants that they belong to an upwardly assimilating minority group that is outperforming many of their peers - both native and immigrant. Research participants spoke clearly to this view: "Muslims are in every field. They're doctors, lawyers, they're pretty successful in general as long as they work towards it" (Marjan). While Ali observes that "the culture is open here... should be a good rate of success for Muslims..." he adds that, relative to other groups, "their success rate should be up..." Hassan reframes Ali's observation in plainer terms: "They [Muslims] have an advantage... In the United States, nobody wants to offend another person. So if a Muslim wasn't seen for a promotion, he's now seen for a promotion. And even though he may have a higher skillset than the other person, it's helping out a lot." In this way, research participants can be seen to reasonably predict a parity of life chances relative 
to other native-born groups, thus conforming to Alba \& Nee's (2003) criteria for assimilation into the American mainstream.

Finding \#3: Shifting the Bright Boundary

Research participants' reactions to post-9/11 contexts of reception took two successive forms: affirmations of a bright boundary within post-9/11 contexts of reception, then identification with the American mainstream. This reaction constitutes a boundary shift, I argue, because there is a meaningful difference between how research participants understand their location within the U.S. mainstream and the way they have been consistently portrayed within post-9/11 contexts of reception. In recounting their experiences of discrimination, research participants indicated a clear awareness of their perceived location outside the mainstream within negative post-9/11 contexts of reception - on the 'other side' of the bright boundary, so to speak. By both affirming the bright boundary and including themselves as members of the American mainstream, they effectively shift their location to the other side.

Where Alba (2005) observes boundary shifting to be comparatively rare, and much less likely in general, the argument can also be made that research participants are correcting what they perceive to be an error in the way the bright boundary has been previously drawn within post-9/11 contexts of reception. Either way, whether the boundary is being shifted or corrected, it is effectively re-drawn by research participants who assert themselves as a meaningful part of the American mainstream. What then 
remains is a blurred boundary between themselves and the mainstream to which they and their families belong. This dynamic is also put forward as another opportunity for future research, and presently hypothesized to subsequently bear upon processes of selective acculturation within blurred boundaries among second generation Muslim immigrants in the U.S.

Affirming the Bright Boundary \& Identifying with the Mainstream

In affirming a bright boundary, research participants primarily focused on a rejection of takfir, or the pronouncement of other Muslims as 'non-Muslims'. Jafar's explanation represents the clearest account of what nearly every research participant generally agreed on: "as long as you do say the Shahada you are a Muslim... If somebody says they're Muslim, they identify as Muslim, then they are Muslim." In stronger, and somewhat paradoxical terms, Hasan argues that "the people, declaring themselves, saying that one Muslim is not a Muslim, those are true non-Muslims."

Thus, the research participants repeatedly consider the perpetrators of terrorist acts to be Muslims. For them, the problem does not appear to be that terrorist acts are referred to as 'Islamic terrorism' in the U.S. media, but instead, that disproportionate visibility results in "Islamophobia, which I understand, but it's really problematic because people know that, well, they just accept what they hear and there's just no need or want to understand the facts for what they are" (Farah). Consider the following comment by Nemah: 
"From the recent actions of the last couple years, 9/11 terrorist attacks, ISIS whatever... it definitely has affected the way that white people, black people, Americans look at Muslims, [and] people from the Middle East. They just put a bad rap on the majority if not everyone that is Muslim.

Researcher: "Do you think that is justified?"

"I would say to an extent it is justified because of the actions [of] some Muslims... But that does not mean that every Muslim should be looked at that way... This is the generation we live in, and I don't think it's very pleasant. I don't think it should be this way, but it is what it is."

These accounts paint a clear picture where research participants see two serious problems to consider, not one as is often implied within post-9/11 contexts of reception. The first is the problem of Islamic terrorism, the second is the problem of its inevitable conflation within the U.S. media. Americans are "getting a narrow view of Muslims and the culture... all they see is what the media is showing, so that is the only picture they get. Many Americans have never met a Muslim, so they don't have anything else to go by" (Marjan). This is where an Orientalized 'Islam' (Kumar, 2010) appears to have its roots within post-9/11 contexts of reception - not in labeling some acts of terrorism as 'Islamic', but in remaining critically unable to distinguish - in properly evaluative and proportional terms, between violent Islamic extremism and the rest of Islam, which happens to include the vast majority of Muslims in the West and 
throughout the world. This 'new Orientalism' appears to be what members of the second generation take issue with and respond to in political terms. It appears to be what they want to talk to non-Muslims about and educate them on while simultaneously placing themselves across the divide from terrorists and on the side of the host nation to which they understand themselves to belong.

\section{Summary}

This section has presented exploratory findings that identify public institutions and gender as particularly fertile grounds for future research on experiences of discrimination among second generation Muslim immigrants within post-9/11 contexts of reception. It suggests support for Alba \& Nee's (2003) emphasis on the important role public institutions play as fundamental enablers for the belief among immigrants in a parity of life chances relative to their native peers through the protection of civil rights in the public sphere. This section has also highlighted gender as an influential factor that should guide future research on the Muslim second generation in the U.S. In particular, the indirect effect of gender through family structure and the visibility of religious dress already has strong parallels in the U.S. immigration research literature from which to draw (Ali, 2005; Williams \& Vashti, 2007) and incorporate into future analyses focusing more squarely on second generation Muslim immigrants. The particularities of an immigrant double consciousness, moreover, have become established in research on Latina women immigrants in the U.S. (Anzaldua, 1987) and 
remain so far unexplored in specific relation to second generation Muslim immigrants within post-9/11 contexts of reception.

Finally, the findings here indicate resilience among research participants within post-9/11 contexts of reception that conform to Alba \& Nee's (2003) definition of 'new assimilation'. Furthermore, in actively affirming the bright boundary between Islamic extremists and the American mainstream while at the same time identifying as members of the American mainstream, research participants effectively shifted the bright boundary to alter their location with respect to it. This touches on the role public institutions play as enablers of such processes, but more importantly to the point at hand: the phenomenon of boundary shifting observed among the small sample of research participants in this exploratory study constitutes promising grounds for future research on second generation Muslim immigrants in the U.S. - especially in relation to their comparatively favorable socioeconomic status relative to other immigrant groups. This further engages with the work of Portes \& Rumbaut (2006) and other immigrations scholars concerned with trajectories of segmented assimilation.

\section{Section 2:}

Research Question \#2: How do second-generation Muslim immigrants in the U.S. construct and maintain religious meaning?

Finding \#4: Constructing Islam: The Role of Family \& Society 
Research participants expressed unilaterally localized constructions of Islam. In their accounts, two external factors emerged as 'pressure points' exerting power and influence on individuals in both how they construct and how they maintain religious meaning; first, through family - representing an 'inner world' and second, through the context of reception - representing an 'outer world' or broader society in the context of reception. From each of these locations the construction or maintenance of religious belief was seen to take on a particular significance. In their 'inner world' of family, for example, research participants appeared to be primarily concerned with the construction of religious meaning. In their 'outer world' defined by post-9/11 contexts of reception, however, the maintenance of religious belief was seen as the main imperative.

Research participants dealt with each external factor (the family, and the context of reception) in two basic ways: by either accepting or rejecting their influence. In order to avoid conceptual ambiguity and confusion surrounding categorical 'acceptance' or 'rejection' of external factors, this study viewed any incorporation of the parents' or families' terms of interaction as a form of acceptance. Clear statements such as: "my parents were raised very religiously, but they never passed on that desire or their beliefs on to me" (Shahin), "Religious wise, I mean, my parents aren't really that religious" (Maryam), or "Not really. I mean, mine is so far from it. My version of religion anyway" (Sholeh) were required to classify a research participant as 'rejecting' familial influence - either because they actively rejected it or it was absent in terms they would describe 
as meaningful. This reflects the findings of existing research on the dynamics of selective acculturation within immigrant families and among the second generation in particular (Foner, 1997; Alba \& Nee, 2003; Portes \& Rumbaut, 2001).

\section{Family \& the Construction of Religious Meaning}

According to the research interviews, the power and influence of family factors served to localize Islam in a distinct way. Acceptance of familial power or influence is therefore referred to as traditionalization, meaning that the second generation is carrying on the traditions of their parents. A rejection or absence of familial power and influence leads to its individualization, meaning research participants constructed an Islam that was individually distinct from that of their family or parents. As emphasized above, some familial influences were observed to emphasize individualism in Islam these accounts are still regarded as 'traditionalized'. Only those research participants who constructed religious meaning in a manner consistent with a rejection or absence of familial influence were regarded as 'individualized'.

Rather interestingly, those who had constructed religious meaning in an individualized manner were seen to be concerned with Islam as a matter of doxa, whereas those who had constructed religious meaning in a traditionalized manner were concerned with Islam as a matter of praxis. That is to say, because Islam is an orthopraxic religion the traditional emphasis is on praxis over doxa. Where differences in belief have been a source of scholarly and juridical debate, differences in practice 
have been a source of outright conflict, defining not only a level of civil strife which became normalized in historical terms but also the root sectarian divisions that continue to define the Islamic world today (Lewis, 1993; Roy, 2004). Those of the secondgeneration who individualize the construction of religious meaning can be seen to so in an orthodox manner, emphasizing the value and meaning of belief itself - irrespective of practice. This reflects the potential influence of the historically dominant (and also orthodox) religion in the U.S., Christianity, insofar as the preexisting practice of religion within host nations have been seen to prefigure the religious practices of immigrants.

\section{Contexts of Reception \& the Maintenance of Religious Meaning}

The power and influence of contemporary discourses on Islam in the U.S. are exerted primarily through post-9/11 contexts of reception, and can also be seen to effectively structure the way members of the second generation maintain religious belief within the public sphere. Here, Portes \& Rumbaut's (2006) account of linear and reactive identity becomes especially useful as a frame of analysis. Consistent with the research literature, interview participants were observed to maintain religious belief in reaction to prevailing discourses on Islam within the context of reception, i.e. the U.S. Hence, their maintenance of religious belief can be said to occur in a reactive manner. That is, they engage with what they hear from non-Muslims in the public sphere in the way they maintain religious meaning. 
Those who reject, or remain otherwise ambivalent toward, the external power and influence of prevailing discourses on Islam within post-9/11 contexts of reception can be seen to maintain religious belief in a linear manner - more preoccupied with 'doing' Islam (whatever that may mean for them) rather than' talking about it'. Where reactive maintenance appears to be dynamic and interactive, linear maintenance appears to be relatively static and interactively passive - at least where post-9/11 contexts of reception are concerned. I offer the following hypothetical empirical model as a hypothesis for the construction and maintenance of religious identity within the 'inner world' of family and the 'outer world' of the context of reception:

Family, U.S. Society \& The Construction of Islam:

\begin{tabular}{|l|l|l|}
\hline & Linear & Reactive \\
\hline Individualized & Linear Individualized Islam (LI) (2 & Reactive Individualized Islam (RI) \\
& Participants) & (2 Participants) \\
\hline Traditionalized & Linear Traditionalized Islam (LT) & Reactive Traditionalized Islam \\
& (3 Participants) & (RT) (3 Participants) \\
\hline
\end{tabular}

Table 3. 


\section{Constructions of Islam: Four Vignettes}

In sum, these findings offer two distinct hypotheses for future research: first, that the family and the context of reception act as two sites where the construction and maintenance of meaning respectively occur within processes of selective acculturation defined by blurred boundaries; and second, that the construction and maintenance of religious meaning is dichotomized at each site such that four rudimentary types can be identified, potentially signaling the unique manner in which Islamic religious markers are being re-embedded within contemporary post-9/11 cultural contexts. Rather interestingly, the pool of 10 research participants itself spread as evenly as possible into the four categories $-2 \mathrm{LI}, 3 \mathrm{LT}, 2 \mathrm{RI}$, and $3 \mathrm{RT}$. What follows are a series of vignettes accounting for and describing each variation in the hypothesized typology.

\section{Linear Individualized Islam}

Two respondents, Nemah and Sholeh, fit this categorization. Consistent with the criteria above, the influence of family is expressly absent in how religious meaning is constructed and understood for both research participants. In response to the question: “In what ways are your parents' religious lives connected with yours?" (Question 13, Appendix A) Sholeh replied that: "They raised us religiously, and I think... they'd be very disappointed." In response to Question 14 (Appendix A): “Do you feel a connection between your religious life and the histories and traditions of your people?", She continued: "Not really. I mean, mine is so far from it. My version of religion anyway." 
Instead of signaling a break with the first generation, Nemah discusses the explicit absence of religious direction or influence from his family concerning Islam: “Religious wise, I mean, my parents aren't really that religious. My mom prays, and of course they have that background, but they don't really implement it into our minds that we should be religious or think this way." His response to Question 14 (Appendix A) is less elaborate and more straightforward: "I mean no, not really." Both research participants describe a clear break with the preceding generation on the question of what Islam is, and what it means.

On the question of religious identity in the public sphere, Nemah was also quite clear: "People who were born in the Middle East are born Muslim, but people who are, ... like my nephew who was just born... is going to be considered Muslim, even though he has a different mindset considering he was born in the United States." According to these sentiments, the act of being 'born Muslim' is as unavoidable as being born in the United States, or anywhere else for that matter. In this way, Islam is something someone inherits and defines individually. In this sense it is not 'practiced' but 'carried' with oneself - alongside many other taken-for-granted attributes that may come to constitute part of one's identity, but with which one may remain ultimately unconcerned with or ambivalent toward.

Reactive Individualized Islam 
Similar to the category above, several respondents fit this categorization. The accounts of separation from familial influence in their constructions of religious meaning also bear striking similarity to the respondents who understood and practiced a Linear Individualized Islam. Shahin for example, stated that: "My parents were raised very religiously, but they never passed on that desire or that, their beliefs, on to me. They wanted to let me discover things by myself." He also adds that, while he considers himself a Muslim, he "was born into it but... not, you know, practicing." Ali strikes a similar vein: “My parents' religious lives, my dad, he's very, um, can't say he's religious. He's more spiritual... he's a Muslim but he doesn't, he's not loud about it or try to preach." Both respondents indicate positive relationships with family, but also a clear break on the question of Islam, in terms of both doxa and praxis. Consequently, both are here classified as constructing an individualized Islam.

The maintenance of religious meaning for Shahin and Ali diverges sharply from the linear accounts of Nemah and Sholeh above. Even though all four research participants construct religious meaning in an individualized manner, they maintain it in fundamentally different ways. Shahin and Ali demonstrate a clear awareness of post9/11 contexts of reception as well as a willingness to engage with them on behalf of Islam, and as Muslims. Consider the following account from Shahin:

"I think that sometimes you have people who could take some words and twist them around in a negative way. 
Researcher: "In what way? What's a 'negative way'?

"Unless you specifically specify what you mean I think there should be kind of an interpreter of what's the Imam or what the person means... I think over the years, a lot of it has changed - the perception, especially after 9/11. I would say that a lot of people are confused and don't really know much. And I think that, I spend a lot of time telling people that I just meet, I tell them about Islam because they wouldn't think that I'm Muslim in the first place."

On this point, Shahin is not only aware about negative stereotypes and continual distortions concerning Islam in the U.S., but also sees himself as an active interlocutor on its behalf. In a general sense, he wants an 'interpreter' to clear up confusions about the religion and the way Muslims are perceived in the U.S. At the same time, however, he is willing to play that role himself. This is one of the clearest examples of reactive maintenance of religious meaning in the public sphere. What one believes is not simply 'carried' with them in the public sphere, but actively 'at issue' - calling upon individuals to invest in the outcome of its public understanding and, consequently, in its social and political significance. Reactive maintenance is of added significance for Shahin, whom people 'wouldn't think was Muslim in the first place' - because he is a light-skinned, blue-eyed Eastern European. He is 'invisible' in an important sense, but instead makes himself visible in order to participate in what he sees as a necessary and important public dialogue. 
While Ali speaks to being more 'visibly Muslim', he is no less committed to a reactive approach toward the maintenance of religious meaning. "If I walk into a room and somebody looks at me with my beard, immediately they might think 'oh, this Muslim guy, I don't know where he's from'. But the moment I communicate with them and interact with them their whole idea of who I was when I walked in the door changes" Ali also adds that he has "been invited to many churches to talk about Islam, or you know, perform a prayer."

These accounts suggest that while Shahin and Ali have constructed Islam in an individualized manner, they maintain religious meaning in a reactive manner. They are not only aware of post-9/11 contexts of reception, but maintain a positive outlook on U.S. society and regard themselves as active participants within its discourses on behalf of Islam. Where Ali uses his apparent visibility as an opportunity to educate others on Islam by confronting their perceptions and stereotypes, Shahin makes himself visible in order to challenge predominant ideas and stereotypes about Islam in a novel way, as well as educate others who may not have known they were speaking or acting with a Muslim individual present.

\section{Linear Traditionalized Islam}

In contrast to those who individualize Islam, Maryam and Hassan provide detailed accounts of how familial power and influence can play a role in the construction of religious meaning. Maryam linked the significance of religion to her culture: “Just cause, 
Muslim, being Muslim, it kind of dictates how our country is run... And being that it is religious, they have to, Iranian people have to follow their customs." Similarly, when asked "How do you see yourself as being connected to the past of your family?"

(Question 12, Appendix A), Hassan responded: "My last name. Praying five times a day. The eating of halal meat, as well as communicating with my family back home... Islam brought our family together." Regarding his parents' religious lives being connected with his own, Hassan continued:

"My parents are at that point in life where they want to practice, and they preach it. I speak to my mother on the phone, she says 'don't forget your prayers', even though I don't pray, as much. Um, my father will only call me just to tell me a verse, how it could relate to my life."

With both Maryam and Hassan we see active engagement, either through culture or explicit religiosity, on behalf of the first generation directed toward the second. Furthermore, such efforts appear to be reflected in their construction and understanding of Islam. In this way, the construction of religious meaning can be seen to be traditionalized for both Maryam and Hassan.

Both research participants were also clearly linear in their maintenance of religious meaning. "Islam basically, to me, is very general for me. More like, being faithful to god. I don't really have much more to go into that... I'm not really religious so I don't really have an opinion of it. I was born Muslim" (Maryam). Consistent with her 
family's influence, Islam is something Maryam 'does' rather than 'believes'. The relevant observation here is not the form of her religiosity, but its consonance with how the connection to her family informs the construction of religious belief - and its attendant maintenance in the public sphere. Hassan demonstrates more clearly how a culturally-rooted and at the same time individually-defined Islam is distinct from what has been here categorized as 'Individualization':

"An Imam in a Mosque, when I was visiting Iran as a kid... he told me every Muslim is going to look up around the mountain and see what path is going to work best for him. And you always think that path works best for you. And it isn't until you get to the top of the mountain, that very peak, you see the thousand different paths that you could have gone up and could have helped you out."

Hassan's account of Islam is both familially-informed, as well as decidedly individualistic in its construction. For Hassan, Islam is individualistic, but not individualized because it is connected quite clearly and firmly to the past and to the teachings of his family. It is linear in maintenance because it is something he quietly carries within himself through a sense of sacred familial obligation, instead of something that is 'at issue' amidst larger dialogue in the public sphere. 


\section{Reactive Traditionalized Islam}

Of all the research participants, the only two females to wear headscarves, both of whom were open and outspoken in their interviews, both fit into this last category. Marjan exhibits a traditionalized construction of religious meaning as well as reactive maintenance. When asked: “In what ways are your parents' religious lives connected with yours?" (Question 13, Appendix A) She responded clearly and unequivocally: "In every way! I grew up in a very strict household, so religion and culture come before anything else. Family always comes first, so I still definitely hold onto a lot of that. It's definitely affected me into adulthood, following the religion and the way we do things." And when discussing Islam, reactive maintenance became apparent: "A lot of times people in the West think that the way Arabs or people from different cultures do things is actually religious when it's not Islam. It's just their culture... A simple way I put it for people who don't really understand religion a lot: Being an American, you live in this country and they have rules. One of the rules is you can't drink when you're under 21 , but how many people actually follow that rule? Does that mean they're not American?" The argumentative nature of how Marjan explains Islam to others indicates both an awareness of contemporary discourses surrounding Islam and her role as an agent on its behalf. She both identifies a source of confusion and actively participates in its clarification. 
Similarly, Farah expresses her view of religion as connected to her family: "Islam is more of a sense of community to me. It's home, it's my family [ in the literal senseimmediate and extended family], it's what I've been raised with..." And her orientation toward the public sphere is stridently reactive: "I have problem with religion in general and the way Islam is perceived cause its perceived more as a cult than a religion..." Evident in Farah's statements are a connection to family and a belief that public perceptions of Islam are both relevant and consequential.

She continues: "But another thing about Muslims is anyone who does something in the name of God or in the name of the Prophet, or in the name of Islam, period, and justifies it as, that's a bad Muslim because they should know better, like anything negative." Farah is not only connected to her family, albeit in a somewhat more contentious manner than others, but also actively aware of and responsive to prevailing discourses surrounding Islam in the public sphere. Both research participants practicing a Reactive Traditionalized Islam are visible representatives of their ethnic communities, as well as accountable Muslim interlocutors in the public sphere. 


\section{Chapter 6}

\section{Conclusion}

This study has conducted an introductory exploration of a small sample of second-generation Muslim immigrants in Portland, Oregon and the critical intersection they occupy between public discourses concerning both Islamophobia and radicalization within post-9/11 contexts of reception. It originally hypothesized that the sudden shift from neutral to comparatively negative contexts of reception brought on by $9 / 11$, combined with the brightening of previously blurred boundaries for Muslims in the U.S., would lead to an increase in the frequency and severity of discrimination experienced by second-generation Muslim immigrants and ultimately result in the formation of reactive identities and the construction of a Globalized Islam.

This research disconfirmed my initial hypotheses. First, the extremely negative general context of reception initiated by $9 / 11$ did not radicalize any of these research participants. They did not engage in a strongly combative reactive identity in response to increased prejudice and discrimination, and none expressed any sympathy for radical Islamic extremists. Instead, their confidence in civil rights protections afforded to them 
by public institutions allowed them to engage in boundary shifting, and the reestablishment of blurred boundaries within which selective acculturation processes can continue.

Some engaged in a different, and importantly innocuous, form of reactive identity formation in the maintenance of religious meaning. And it is significant to note here that the reactive maintenance of religious meaning was found to be relatively incongruous with prior definitions of reactive ethnicity formation (Portes \& Rumbaut, 2006). In prior research, reactive identity formation has been identified as a largely negative outcome in response to social and economic discrimination as well as family conflicts. Its consequences have been significant for the structural integration of immigrant communities and the individual well-being of their children. This may reflect a difference in the role of reactivity within processes of identity construction versus identity maintenance - where prior research may have captured reactivity in identity construction, whereas it has here been encountered in relation to identity maintenance. In any case, the role of reactivity observed among research participants in this study does not appear to conform to the more problematic manifestations of reactive identity formation documented among immigrants in the U.S. or in Europe. In fact, it can be seen as relatively congruous with other forms of identity maintenance within a polarized American mainstream repeatedly conditioned and evolved within the perpetual historical shockwaves of immigration and larger global events. 
Beyond this, the study identified a number of emergent differences in how participants both experienced and reacted to comparatively negative post-9/11 contexts of reception. First, they recognized that 9/11 transformed what had been in Alba's (2005) terms a blurred boundary between Islamic immigrants and the U.S. society into a bright and often impermeable difference. These second-generation immigrants responded by moving the bright boundary and defining it not as one that distinguished all Islamic adherents from U.S. society, but instead only those who were Islamic militant extremists were on the other side of the bright boundary. Moderate Muslims, which included all the respondents in this study, felt that the boundary between them and U.S. society was still a blurred boundary, a boundary that would not impede their assimilation and success in U.S. society.

By both identifying with the mainstream and affirming bright boundaries, research participants effectively shifted the boundary to alter their locations with respect to it. In this context, they actively reestablished blurred boundaries between themselves and the cultural mainstream, thus enabling processes of selective acculturation to continue. By learning English and gaining advanced education, they became (or at least perceive that they become) a part of U.S. society at the same time that they maintained their belief in Islam and at least partial continuation of their parents' homeland cultures. This process was facilitated, crucially, by the perceived character and role of public institutions operating on their behalf. 
Despite their experiences of discrimination by individuals and private organizations, research participants expressed strong confidence in the protections afforded to them by state institutions against discrimination. As a result, they were able to 'reasonably predict a parity of life chances' relative to their peers in the cultural mainstream. These results suggest support for Alba \& Nee's (2003) definition of contemporary assimilation as well as its potential for use among Muslim immigrant populations as an analytical lens in future research.

Beyond facilitating assimilation and enabling boundary shifting, the role of public institutions also emerged as a critical factor in shaping experiences of discrimination among the research participants. Experiences of discrimination attributable to individuals or private organizations were often dismissed as 'ignorant', and research participants exhibited great resilience toward discrimination in this regard.

Discrimination by public institutions, especially in the context of those occupying positions of power, were seen to be particularly consequential by all accounts. These experiences appeared to deeply affect research participants on a personal level as well as potentially undermine their confidence in the protections afforded to them in the public sphere by the larger society. As a result, the role of public institutions was seen as the most important determinant of the relative harm caused by experiences of discrimination for research participants. 
The second research question asked: How do second-generation Muslim immigrants construct and maintain religious meaning? Here research participants were seen to unilaterally construct Islam in a localized manner, aligning with the research literature's extensive accounting of how religious meaning is being constructed among the vast majority of second generation Muslims in the West. The 'inner world' of family and the 'outer world' of the larger society - defined primarily by the context of reception, were seen as key sites where religious meaning was respectively constructed and maintained within selective acculturation processes enabled by (at least the perception of) blurred boundaries. This suggests support for Portes \& Rumbaut's (2001) account of family and society as key influential factors for processes of selective acculturation within large coethnic communities absent intergenerational conflicts.

The hypothetical typology of Islamic religious identity has also been put forward in this study. It is based on the dichotomization of the construction and maintenance of religious meaning at each site within the selective acculturation process. In either accepting or rejecting familial influence, religious meaning is identified as being respectively 'traditionalized' or 'individualized' in its construction. Similarly, in either accepting or rejecting the influence of public discourses on Islam within post-9/11 context of reception, religious meaning is identified as being respectively 'reactive' or 'linear' in its maintenance. Thus, four hypothetical variants can be seen to emerge that potentially indicate the way in which Islamic religious markers are being re-embedded within post-9/11 contexts of reception and used to construct politically-salient religious 
identities among the research participants. This approach reflects, furthermore, Stepick \& Stepick's (2010) important call for future research on the children of immigrants to explore the "complex processes and trends rather than discrete social divisions" (14) such as their country of origin. By focusing on the Muslim second generation in the U.S., this exploratory study has attempted to do just that.

The limitations of these results have also been made quite clear in this study. With such a small sample size, no meaningful generalizations are possible. What this study has achieved are only tentative, suggestive findings that offer important and focused hypotheses for future research. The sampling method undertaken here for exploratory purposes will be inadequate for the purposes of future research. Future research methods must move beyond convenience sampling, include many more participants and ultimately reflect more accurately in their composition the population they seek to explore. In order to address the fertile grounds for future research that have been identified and test the hypotheses that were the aim of this exploratory study to produce, a larger sample population, truly random sampling and a diverse array of research methods must be employed.

\section{Summary of Contributions:}

Research Question \#1: How have second generation Muslim immigrants in the U.S. experienced and reacted to post-9/11 contexts of reception? 
This research has identified two factors, public institutions and gender, as particularly fertile grounds for future research on experiences of discrimination within post-9/11 contexts of reception among second generation Muslim immigrants. It has also offered a hypothetical model that identifies the relative consequentiality of different actors as sources of discrimination - according to whether they are individuals or organizations that are public or private in nature. This finding suggests support for Alba \& Nee's (2003) emphasis on the importance of public institutions in the assimilation process.

This research has also identified the successful assimilation of research participants into the U.S. mainstream in a manner consistent with Alba \& Nee's (2003) definition of: a reasonable belief in parity of life chances relative to their peers in the mainstream. It has highlighted their resilience within post-9/11 contexts of reception as fertile grounds for future research in this context, hypothesizing that in both affirming bright boundaries within post-9/11 contexts of reception and also actively identifying as members of the U.S. mainstream, research participants effectively shift their location with respect to the bright boundary and reestablish blurred boundaries.

Research Question \#2: How do second generation Muslim immigrants construct and maintain religious meaning?

This research has emphasized the political-salience of Islamic religious identity within contemporary post-9/11 contexts of reception. It has put forward the hypothesis 
that the family and the context of reception act as two sites where the construction and maintenance of religious meaning occur, respectively, within processes of selective acculturation defined by blurred boundaries. It has further hypothesized that the construction and maintenance of religious meaning are dichotomized at each site, and offered a hypothetical typology identifying four rudimentary forms of religious identity that may be emerging among second generation Muslim immigrants today.

\section{Directions for Future Research}

\section{1) Exploring Post-9/11 Contexts of Reception}

Extending the previous work of immigration scholars to specifically address the complexity of post-9/11 contexts of reception remains an unfinished analytical task future research should address. Semi-structured in-depth interviews with members of the first generation should be conducted in order to incorporate their accounts and experiences of the shift between pre and post-9/11 environments. The addition of data from the second generation in specific relation to post-9/11 contexts of reception, furthermore, would provide a more complete account among the population of Muslim immigrants as a whole, and importantly build upon and refine the accounts that have been presented in this exploratory study. A fuller account of post-9/11 contexts of reception and their effects on Muslim immigrants in the U.S. may also enable a range of comparative analyses vis a vis the European research literature. 
2) The Politics of Boundary Processes Among Muslim Immigrants in the Post-9/11 Era

Future research should explore the relationship between boundary processes and various forms of political identity in the context of the Muslim Second Generation. Specifically, the relationships between Localized Islam and Selective Acculturation, and between Globalized Islam and Boundary Crossing requires further exploration and clarification. Particular attention should be paid to the role of historical consciousness and familial culture in the construction of various religious identities, as well as to transnational migration and the impact of social media in shifting the fundamental dynamics and key demographics of this terrain.

Of particular interest should be the role of social media in complicating the geographical rootedness of bright and blurred boundaries, and the acculturation processes of immigrants in relation to them. For example: has the 'convergence of space' brought on by the proliferation of social media within the transnational immigrant class allowed blurred boundaries to be established and maintained between host nations and immigrants' countries of origin? And what role does social media play in the formation and maintenance of bright boundaries among second generation immigrant populations within Western host nations?

3) The Role of Gender 
Research exploring the influence of gender must work to meaningfully address second generation Muslim immigrants beyond the conventions of contemporary domestic discourses in the U.S. Extending work on immigrants' 'two worlds' and the idea of a double consciousness to new groups would certainly be a worthwhile scholarly endeavor. Future research following this research may focus on qualitative accounts of double consciousness among Muslim immigrants and its gendered impact on processes of selective acculturation, particularly in relation to the issues of religious dress and religious intermarriage.

\section{4) The Role of Public Institutions}

Future research should also go beyond simply identifying the important role public institutions play in mediating experiences of discrimination and their consequences. It is critical to also examine the myriad ways that trust is established in state institutions, the factors that incline or disincline them toward discrimination against Muslims, and the larger role they play in enabling contemporary processes of assimilation to occur among such an ethnically-diverse and geographically-diffuse population.

5) Islamic Religious Identity in the U.S.

The final research direction identified by this pilot study concerns extending the hypothetical typology to explore its salience as a model and its potential generalizability. 
In addition to exploring across disparate geographies at the national, regional, and local levels, future research should also consider how these factors vary in relation to family and society as external 'pressure points' respectively influencing the construction and maintenance of religious meaning within processes of selective acculturation. Beyond the second generation, exploring how Islam is being redefined in the American context, as Judaism and Catholicism in the $20^{\text {th }}$ century before it (Alba \& Nee, 2003), remains a critically-important scholarly task and opportunity for future research farther down the road. 


\section{References}

Abaza, M., \& Stauth, G. (1988). Occidental reason, orientalism, Islamic fundamentalism: A critique. International Sociology, 3(4), 343-364.

Abbas, T. (2004). After 9/11: British South Asian Muslims, Islamophobia, multiculturalism, and the state. American Journal of Islamic Social Sciences, 21(3), 26-38. Abbas, T. (2012). The symbiotic relationship between Islamophobia and radicalisation. Critical Studies on Terrorism, 5(3), 345-358.

Achcar, G. (2008). Orientalism in reverse.

Aidi, H. (2004). "Verily, there is only one hip-hop Umma": Islam, cultural protest and Urban marginality. Socialism and Democracy, 18(2), 107-126.

Adida, C. L., Laitin, D. D., \& Valfort, M. A. (2010). Identifying barriers to Muslim integration in France. Proceedings of the National Academy of Sciences, 107(52), 2238422390.

Ajrouch, K. J., \& Kusow, A. M. (2007). Racial and religious contexts: Situational identities among Lebanese and Somali Muslim immigrants. Ethnic and Racial Studies, 30(1), 72-94. Ajrouch, K. J., \& Jamal, A. (2007). Assimilating to a white identity: The case of Arab Americans. International Migration Review, 41(4), 860-879.

Akyol, M. (2011). Islam without extremes: A Muslim case for liberty. WW Norton \& Company.

Alba, R., \& Nee, V. (1997). Rethinking assimilation theory for a new era of immigration. International migration review, 826-874. 
Alba, R. (2005). Bright vs. blurred boundaries: Second-generation assimilation and exclusion in France, Germany, and the United States. Ethnic and racial studies, 28(1), 2049.

Alba, R. (2008). Why we still need a theory of mainstream assimilation. Migration und Integration. Kölner Zeitschrift für Soziologie und Sozialpsychologie. Sonderheft, 48(2008), $37-56$.

Alba, R., \& Nee, V. (2009). Remaking the American mainstream: Assimilation and contemporary immigration. Harvard University Press.

Alexander, J. C. (2013). Struggling over the mode of incorporation: backlash against multiculturalism in Europe. Ethnic and Racial Studies, 36(4), 531-556.

Algan, Y., Dustmann, C., Glitz, A., \& Manning, A. (2009). The economic situation of firstand second-generation immigrants in France, Germany, and the UK.

Allen, J. P., \& Turner, E. (1996). Spatial patterns of immigrant assimilation. The Professional Geographer, $48(2), 140-155$

Ali, S. (2005). Why Here, Why Now? Young Muslim Women Wearing Hijāb. The Muslim World, 95(4), 515-530.

Allen, J. P., \& Turner, E. (1996). Ethnic diversity and segregation in the new Los Angeles. Ethnicity: Geographic perspectives on ethnic change in modern cities, 1-29.

Anzaldúa, G. (1987). Borderlands: la frontera (Vol. 3). San Francisco: Aunt Lute. 
Anzaldua, G. (1987). How to tame a wild tongue. na.

Armstrong, K. (1994). A history of God. Random House LLC.

Bail, C. A. (2012). The fringe effect civil society organizations and the evolution of media discourse about Islam since the September 11th attacks. American Sociological Review, 77(6), 855-879.

Bakalian, A. P. (1993). Armenian-Americans: from being to feeling Armenian. Transaction Publishers.

Bastenier, A. (1991) The Islamic East in the West. A Few Coordinates. Religioni e Societa $6: 12$

Berry, J. W. (2001). A psychology of immigration. Journal of social issues, 57(3), 615-631. Bilgrami, A. (2012). Islam and the West: Conflict, democracy, identity. Philosophy \& Social Criticism, 38: 477

Bisin, A., Patacchini, E., Verdier, T., \& Zenou, Y. (2008). Are Muslim immigrants different in terms of cultural integration?. Journal of the European Economic Association, 6(2-3), 445-456.

Bleich, E. (2012). Defining and researching Islamophobia. Review of Middle East Studies, 46(02), 180-189.

Bloemraad, I., Korteweg, A., \& Yurdakul, G. (2008). Citizenship and immigration:

Multiculturalism, assimilation, and challenges to the nation-state. Sociology, 34(1), 153.

Bozorgmehr, M. (1997). Internal Ethnicity: Iranians in Los Angeles. Sociological Perspectives, 40(3), 387-408. 
Brettell, C. (2000). Theorizing migration in anthropology. Migration theory. Talking across disciplines, 97-137.

Brettell, C. B., \& Hollifield, J. F. (Eds.). (2014). Migration theory: Talking across

disciplines. Routledge.

Brubaker, R. (2012). Religion and nationalism: Four approaches. Nations and

nationalism, 18(1), 2-20.

Brubaker, R. (2013). Language, religion and the politics of difference. Nations and Nationalism, 19(1), 1-20.

Brubaker, R. (2013). Categories of analysis and categories of practice: A note on the study of Muslims in European countries of immigration. Ethnic and Racial Studies, 36(1), 1-8.

Brubaker, R. (2009). Ethnicity, race, and nationalism. Annual Review of Sociology, 35, 2142.

Bunt, G. (2003). Islam in the digital age. E-Jihad. Online Fatwas and Ciber Islamic Environments, Pluto.

Butler, J. (2011). The power of religion in the public sphere. Columbia University Press. Cabrera, J. F., Scholz, S., Hobor, G., \& Lizardo, O. (2017). Integrating “standard” residents into "non-standard" communities: a longitudinal analysis of social capital in a new urbanist development. Journal of Urbanism: International Research on Placemaking and Urban Sustainability, 10(1), 63-76. 
Castles, S. (2009). World population movements, diversity, and education. The Routledge international companion to multicultural education, 49-61.

Cesari, J. (2009). Muslims in the West after 9/11: religion, politics and law. Routledge. Cesari, J. (2012). The securitization of Islam in Europe. Research Paper, (15).

Connor, P. (2010). Contexts of immigrant receptivity and immigrant religious outcomes: the case of Muslims in Western Europe. Ethnic and Racial Studies, 33(3), 376-403. Chesterton, G. K. (2013). Orthodoxy. Moody Publishers. Crul, M., \& Vermeulen, H. (2003). The second generation in Europe. International migration review, 37(4), 965-986.

Diehl, C., Koenig, M., \& Ruckdeschel, K. (2009). Religiosity and gender equality: comparing natives and Muslim migrants in Germany. Ethnic and Racial Studies, 32(2), 278-301.

Dolezal, M., Helbling, M., \& Hutter, S. (2010). Debating Islam in Austria, Germany and Switzerland: ethnic citizenship, church-state relations and right-wing populism. West European Politics, 33(2), 171-190.

Duderija, A. (2007). Literature review: Identity construction in the context of being a minority immigrant religion: The case of western-born Muslims. Immigrants \& Minorities, 25(2), 141-162.

Edgell, P. (2012). A cultural sociology of religion: New directions. Annual Review of Sociology, 38, 247-265.

Erikson, E. H. (1994). Identity: Youth and crisis (No. 7). WW Norton \& Company. 
Esack, F. (2005). The Qur'an: A User's Guide: a Guide to Its Key Themes, History and Interpretation. Oneworld Publications Limited.

Eyadat, Z. (2012). Islams Between dialoguing and mainstreaming. Philosophy \& Social Criticism, 38(4-5), 507-516.

Ferrari, S. (2002) Law and Religion between Multiculturalism and Identity. The Question of the Juridical Status of Islam in Europe. Migration Studies. 39:147 601-616

Foner, N. (1997). The immigrant family: Cultural legacies and cultural changes. International migration review, 961-974.

Foner, N., \& Alba, R. (2008). Immigrant religion in the US and Western Europe: Bridge or barrier to inclusion?. International Migration Review, 42(2), 360-392.

Fleischmann, F., \& Phalet, K. (2012). Integration and religiosity among the Turkish second generation in Europe: A comparative analysis across four capital cities. Ethnic and Racial Studies, 35(2), 320-341.

Fox, J., \& Akbaba, Y. (2015). Securitization of Islam and religious discrimination: Religious minorities in Western democracies, 1990-2008. Comparative European Politics, 13(2), 175-197.

Gans, H. J. (1979). Symbolic ethnicity: The future of ethnic groups and cultures in America*. Ethnic and racial studies, 2(1), 1-20.

Gans, H. J. (1994). Symbolic ethnicity and symbolic religiosity: Towards a comparison of ethnic and religious acculturation. Ethnic and Racial Studies, 17(4), 577-592.

Gest, J. (2012) Western Muslim Integration Review of Middle East Studies 46:2 
Gholami, R. (2014). 'Is This Islamic Enough?' Intra-Diasporic Secularism and Religious Experience in the Shi'a Iranian Diaspora in London. Journal of Ethnic and Migration Studies, 40(1), 60-78.

Göle, N. (2011). The public visibility of Islam and European politics of resentment: The minarets-mosques debate. Philosophy \& Social Criticism, 37(4), 383-392.

Guarnizo, L. E., Portes, A., \& Haller, W. (2003). Assimilation and Transnationalism:

Determinants of Transnational Political Action among Contemporary Migrants1. American journal of sociology, 108(6), 1211-1248.

Hashem, M. (1991). Assimilation in American Life: An Islamic Perspective. The American Journal of Islamic Social Sciences, 1(1), 83.

Hempel, C. G. (1965). Fundamentals of taxonomy. Aspects of scientific explanation, 137, 154.

Jarvis, H., \& Bonnett, A. (2013). Progressive nostalgia in novel living arrangements: A counterpoint to neo-traditional new urbanism?. Urban Studies, 50(11), 2349-2370. Jasso, G. (1997). Migration and the dynamics of family phenomena. Immigration and the family: Research and policy on US immigrants, 3-46.

Jung, M. K. (2009). The Racial Unconscious of Assimilation Theory. Du Bois Review: Social Science Research on Race, 6(02), 375-395.

Kasinitz, P. (2012, September). The Sociology of International Migration: Where We Have Been; Where Do We Go from Here? 1. In Sociological Forum (Vol. 27, No. 3, pp. 579-590). Blackwell Publishing Ltd. 
Kasinitz, P., Mollenkopf, J., \& Waters, M. C. (2002). Becoming American/becoming New Yorkers: Immigrant incorporation in a majority minority city. International Migration Review, 36(4), 1020-1036.

Kennedy, H. N. (2007). The great Arab conquests: How the spread of Islam changed the world we live in. Da Capo Press.

Kepel, G. (2004). The war for Muslim minds: Islam and the West. Harvard University Press.

Kimball, C. (2011). When religion becomes lethal: The explosive mix of politics and religion in Judaism, Christianity, and Islam. John Wiley \& Sons.

Kivisto, P. (2004). What is the canonical theory of assimilation?. Journal of the History of the Behavioral Sciences, 40(2), 149-163.

Kivisto, P., \& Faist, T. (2009). Beyond a border: The causes and consequences of contemporary immigration. Sage Publications.

Klug, B. (2012). Islamophobia: A concept comes of age. Ethnicities, 12(5), 665-681. Koopmans, R. (2013). Multiculturalism and immigration: A contested field in crossnational comparison. Annual Review of Sociology, 39, 147-169.

Korteweg, A., \& Yurdakul, G. (2009). Islam, gender, and immigrant integration: Boundary drawing in discourses on honour killing in the Netherlands and Germany. Ethnic and Racial Studies, 32(2), 218-238.

Korteweg, A. C., \& Yurdakul, G. (2010). Religion, Culture and the Politicization of Honour-Related Violence. A Critical Analysis of Media and Policy Debates in Western 
Europe and North America. Genf: United Nations Research Institute for Social

Development.

Kumar, D. (2010). Framing Islam: The resurgence of Orientalism during the Bush II era. Journal of Communication Inquiry.

Leiken, R. S. (2005). Europe's angry Muslims. Foreign Affairs, 84(4), 120-135.

Lewis, B. (1993). Islam and the West. Oxford University Press.

Lewis, B. (1999). From babel to dragomans. In Proceedings - British Academy (Vol. 101, pp. 37-54). Oxford University Press

Lund, H. (2003). Testing the claims of new urbanism: Local access, pedestrian travel, and neighboring behaviors. Journal of the American Planning Association, 69(4), 414-429.

Lynch, O., \& Veale, A. (2015). Being Muslim and being Irish after 9/11: self-conceptions of place in Irish society. Ethnic and Racial Studies, 38(11), 2003-2018.

Mamdani, M. (2002). Good Muslim, bad Muslim: A political perspective on culture and terrorism. American anthropologist, 104(3), 766-775.

Mandaville, P. (2007). Globalization and the politics of religious knowledge: Pluralizing authority in the Muslim world. Theory, Culture \& Society, 24(2), 101-115.

Marechal, B. (2002) Integration of Islam and Islamic Communities in Europe: An Assessment. Migration Studies. 39:147 577-599

Marranci, G. (2004). Multiculturalism, Islam and the clash of civilisations theory: rethinking Islamophobia. Culture and Religion, 5(1), 105-117. 
Mårtensson, U. (2007). The power of subject: Weber, Foucault and Islam. Critique:

Critical Middle Eastern Studies, 16(2), 97-136.

Massey, D. S. (1999). International migration at the dawn of the twenty-first century:

The role of the state. Population and Development Review, 25(2), 303-322.

Mavelli, L. (2013). Europe's encounter with Islam: the secular and the postsecular.

Routledge.

Mishra, S. (2008). Islam and Democracy Comparing Post-9/11 Representations in the

Turkish, Iraqi, and Iranian Contexts. Journal of Communication Inquiry, 32(2), 155-178.

Prestige Press

Modarres, A. (1998). Settlement patterns of Iranians in the United States. Iranian

Studies, 31(1), 31-49.

Moghissi, H. (1999). Away from home: Iranian women, displacement cultural resistance and change. Journal of Comparative Family Studies, 207-217.

Naber, N. (2005). Muslim first, Arab second: A strategic politics of race and gender. The Muslim World, 95(4), 479-495.

Naber, N. (2006). The Rules of Forced Engagement Race, Gender, and the Culture of

Fear among Arab Immigrants in San Francisco Post-9/11. Cultural Dynamics, 18(3), 235-

267.

Nagel, C. \& Staeheli, L. (2011) Muslim Political Activism or Political Activism by Muslims? Secular and Religious Identities Amongst Muslim Arab Activists in the United States and United Kingdom. Identities: Global Studies in Culture and Power 18:437-458 
Nisbet, E. C., Ostman, R., \& Shanahan, J. (2008). Public opinion toward Muslim Americans: Civil liberties and the role of religiosity, ideology, and media use. Muslims in Western politics, 161-199.

Nisbet, E., Ortiz, M., Miller, Y., \& Smith, A. (2011). THE “BIN LADEN” EFFECT: HOW AMERICAN PUBLIC OPINION ABOUT MUSLIM AMERICANS SHIFTED IN THE WAKE OF OSAMA BIN LADEN'S DEATH. School of Communication, Ohio State University. Retrieved Oct, 15, 2011.

Ozyurt, S. Ş. (2010). Bridge Builders or Boundary Markers? The Role of the Mosque in the Acculturation Process of Immigrant Muslim Women in the United States. Journal of Muslim Minority Affairs, 30(3), 295-315.

Padín, J. A. (2005). The normative mulattoes: The press, Latinos, and the racial climate on the moving immigration frontier. Sociological perspectives, 48(1), 49-75.

Parrillo, V. N., \& Donoghue, C. (2005). Updating the Bogardus social distance studies: a new national survey. The Social Science Journal, 42(2), 257-271.

Perlmann, J., \& Waldinger, R. (1997). Second generation decline? Children of immigrants, past and present-a reconsideration. International migration review, 893922.

Peek, L. (2005). Becoming Muslim: The development of a religious identity. Sociology of religion, 66(3), 215-242.

Piazza, J. A. (2011). Poverty, minority economic discrimination, and domestic terrorism. Journal of Peace Research, 48(3), 339-353. 
Portes, A. (1997). Immigration theory for a new century: Some problems and opportunities. International migration review, 799-825.

Portes, A., \& Böröcz, J. (1989). Contemporary immigration: Theoretical perspectives on its determinants and modes of incorporation. International migration review, 606-630. Portes, A., Fernandez-Kelly, P., \& Haller, W. (2005). Segmented assimilation on the ground: The new second generation in early adulthood. Ethnic and racial studies, 28(6), $1000-1040$

Portes, A., \& Rumbaut, R. G. (2006). Immigrant America: a portrait. Univ of California Press.

Portes, A., \& Stepick, A. (1993). City on the edge: The transformation of Miami. Univ of California Press.

Portes, A., \& Zhou, M. (1993). The new second generation: Segmented assimilation and its variants. The annals of the American academy of political and social science, 530(1), 74-96.

Prothero, S. (2011). God is Not One: The Eight Rival Religions That Run the World, And Why Their Differences Matter. Black Inc.

Post, J. M., \& Sheffer, G. (2006). Risk of Radicalization and Terrorism in US Muslim Communities, The. Brown J. World Aff., 13, 101.

Rahman, F. (1999). Revival and reform in Islam. Oneworld Publications.

Rosenow-Williams, K. (2012). Organizing Muslims and Integrating Islam in Germany: New Developments in the 21st Century. Brill. 
Roy, O. (2004). Globalized Islam: The search for a new ummah. Columbia University Press.

Sadowski, Y. (2006). Political islam: Asking the wrong questions?. Annu. Rev. Polit. Sci., 9, 215-240.

Saeed, A. (2006). Fazlur Rahman: A Framework for Interpreting the Ethico-Legal Content of the Qur'an'. Modern Muslim intellectuals and the Qur'an. New York, 37-65.

Said, E. (1979). Orientalism. 1978. New York: Vintage, 1994.

Sayyid, S., \& Vakil, A. (Eds.). (2010). Thinking through islamophobia: global perspectives. Cinco Puntos Press.

Semati, M. (2010). Islamophobia, culture and race in the age of empire. Cultural Studies, $24(2), 256-275$.

Shaheen, J. (2012). Guilty: Hollywood's Verdict on Arabs After 9/11: Hollywood's Verdict on Arabs After 9/11. Interlink Publishing.

Silberman, R., Alba, R., \& Fournier, I. (2007). Segmented assimilation in France? Discrimination in the labour market against the second generation. Ethnic and Racial studies, 30(1), 1-27.

Sinno, A. H. (2009). Muslims in Western politics. Indiana University Press. Sinno, A. (2012) The Politics of Western Muslims. Review of Middle East Studies. 46:2 216-231

Sirseloudi, M. (2012). The Meaning of Religion and Identity for the Violent Radicalisation of the Turkish Diaspora in Germany. Terrorism and Political Violence, 24(5), 807-824. 
Song, Y., \& Knaap, G. J. (2004). Measuring urban form: Is Portland winning the war on sprawl?. Journal of the American Planning Association, 70(2), 210-225.

Stemmann, J. J. E. (2006). Middle East Salafism's influence and the radicalization of Muslim communities in Europe. Middle East Review of International Affairs, 10(3). Strabac, Z., \& Listhaug, O. (2008). Anti-Muslim prejudice in Europe: A multilevel analysis of survey data from 30 countries. Social Science Research, 37(1), 268-286.

Stepick, A., \& Stepick, C. D. (2009, September). Diverse contexts of reception and feelings of belonging. In Forum Qualitative Sozialforschung/Forum: Qualitative Social Research (Vol. 10, No. 3).

Stepick, A., \& Stepick, C. D. (2010). The complexities and confusions of segmented assimilation. Ethnic and Racial Studies, 33(7), 1149-1167.

Stern, J. (2003, September). Terror in the name of God: Why religious militants kill. New York: Ecco.

Thomas, W. I., \& Thomas, D. S. (1970). Situations defined as real are real in their consequences. Social psychology through symbolic interaction, 154-155.

Timmerman, C., Vanderwaeren, E., \& Crul, M. (2003). The second generation in Belgium. International migration review, 37(4), 1065-1090.

Trudeau, D., \& Kaplan, J. (2016). Is there diversity in the New Urbanism? Analyzing the demographic characteristics of New Urbanist neighborhoods in the United States. Urban Geography, 37(3), 458-482. 
Vidino, L. (2009). Homegrown jihadist terrorism in the United States: A new and occasional phenomenon?. Studies in Conflict \& Terrorism, 32(1), 1-17.

Voas, D., \& Fleischmann, F. (2012). Islam moves west: religious change in the first and second generations. Annual review of sociology, 38, 525-545.

Waters, M. C., Tran, V. C., Kasinitz, P., \& Mollenkopf, J. H. (2010). Segmented assimilation revisited: types of acculturation and socioeconomic mobility in young adulthood. Ethnic and Racial Studies, 33(7), 1168-1193.

Wike, R., \& Grim, B. J. (2010). Western views toward Muslims: Evidence from a 2006 cross-national survey. International journal of public opinion research, edq002.

Williams, R. H., \& Vashi, G. (2007). Hijab and American Muslim women: Creating the space for autonomous selves. Sociology of Religion, 68(3), 269-287.

Yenigun, H. I. (2004). Muslims and the Media after 9/11: A Muslim Discourse in the American Media?. American Journal of Islamic Social Sciences, 21(3), 39-69.

Yildiz, A. A., \& Verkuyten, M. (2012). 'We are not terrorists': Turkish Muslim organizations and the construction of a moral identity. Ethnicities, 1468796812451219. Yükleyen, A., \& Yurdakul, G. (2011). Islamic activism and immigrant integration: Turkish organizations in Germany. Immigrants \& Minorities, 29(01), 64-85.

Zaidi, A. H. (2007). A Critical Misunderstanding Islam and Dialogue in the Human Sciences. International Sociology, 22(4), 411-434.

Zhou, M. (1997). Segmented assimilation: Issues, controversies, and recent research on the new second generation. International migration review, 975-1008. 
Zhou, M., \& Lee, J. (2007). Becoming Ethnic or Becoming American?. Du Bois Review: Social Science and Research on Race, 4(01), 189-205. 


\section{Appendix A}

Interview Questions:

Constructions of Islam

1) What is your definition of Islam? What does it mean to you in your own words?

2) Are there major differences between you and other Muslims on the question of what Islam means? Or would you say there are more similarities between you than differences? If so, what are they? What points of agreement/disagreement can you highlight?

3) More broadly, who do you believe is or is not legitimately a Muslim? Where are the boundaries, if any, in your opinion?

4) What about Muslims from different countries, such as Egypt, Lebanon, Iran, Indonesia, or Saudi Arabia? How do ethnic backgrounds and traditional cultures shape Islam in these regions? What about your parent's country of origin?

5) What do you believe should be the role of unique local traditions and cultures in Islam? Do they add to or subtract from it?

The U.S. Mainstream 
6) Does living in America help or hinder your ability to live as a Muslim and practice Islam faithfully? Describe your personal experience and your perception of Muslims in the U.S.

7) Do you see American society more as friendly or more as hostile toward Islam? What about Muslims?

a. (If answer focuses on themselves) How would you characterize the experiences of friendliness or hostility from other U.S. Muslims? Examples?

8) For you, what does it mean to be successful in America? Do you believe it possible for Muslims to succeed in America? Do they have the same chances for success as everyone else or not? Why?

9) Looking at yourself, how do you personally see yourself within American society? Do you see yourself as 'inside' or 'outside' of it? Are you a 'member'? How do you believe American society sees you personally? (Probe for who the respondent is thinking of when he/she responds, eg, employer, fellow workers or students, neighbors, etc. Ask for examples.)

10) Are their tension points you see between yourself as a Muslim and as an American? What are they in your opinion? Do you feel them in your daily life? Or are they more subtle and/or pervasive?

11) Do you 'live in two worlds' or one, or more than two? (Probe)

Family 
12) How do you see yourself as being connected to the past of your family?

13) In what ways are your parents' religious lives connected with yours?

14) Do you feel a connection between your religious life and the histories and traditions of your people?

15) Are any of there points of contention between you and your family on issues relating to Islam or American society?

16) How would you describe your relationship with your parents/family (grandparents, uncles, aunts, cousins etc...) more generally?

Friends

17) How many friends would you say you have? How often do you see them?

18) Do you have friends from many different groups? Only a few? Which groups?

19) What relationships are most important to you?

20) Some people don't have many friends or associate with that many people, but have a ton of friends online. How active are you on social media? How do you spend most of your time online - studying, socializing etc...?

Demographic Controls

What is your age?

What is your occupation/Income?

What is your highest level of schooling?

Are you married?

What is your family's country of origin? 


\section{Appendix B}

\section{INFORMED CONSENT FORM}

You are invited to participate in a research study conducted by Shahriyar from Portland State University, Department of Sociology. The researcher hopes to learn about the factors that shape what Islam means in the U.S. today for the children of Muslim immigrants, their family dynamics, and their experiences interacting within the larger society. You were selected as a possible participant in this study because you are between the ages of 18 and 35 , and have at least one parent who is a first-generation Muslim immigrant.

If you decide to participate, you will be included in a one-on-one interview involving a series of short questions that will be digitally recorded. While participating in this study it is possible that you may wish to stop, or continue at a later time. Please feel free to exercise these options at any time you see fit. You may not receive any direct benefit from taking part in this study, but the study may help to increase knowledge which may help others in the future.

Any information that is obtained in connection with this study and that can be linked to you or identify you will be kept confidential. This information will be kept confidential by the interviewer and the research team. Interviews will be coded to preserve anonymity, 
and transcribed onto a password-protected computer with an encrypted hard drive. Pseudonyms will also be used for publication to protect the identities of all research participants.

Your participation is voluntary. You do not have to take part in this study, and it will not affect your relationship with Portland State University. You may also withdraw from this study at any time without affecting your relationship with Portland State University.

If you have questions or concerns about your participation in this study, contact Shahriyar Smith at 503-725-9025. If you have concerns about your rights as a research subject, please contact the PSU Office of Research Integrity, 1600 SW 4th Ave., Market Center Building, Ste. 620, Portland, OR; phone (503) 725-2227 or 1 (877) 480-4400.

Your signature indicates that you have read and understand the above information and agree to take part in this study. The researcher should provide you with a copy of this form for your own records.

Signature

Date

Print name 